Article

\title{
Design of Microgrid Protection Schemes Using PSCAD/EMTDC and ETAP Programs
}

\author{
Hyun Shin ${ }^{1}$, Sang Heon Chae ${ }^{2}$ and Eel-Hwan Kim ${ }^{3, *}$ \\ Faculty of Applied Energy System, Jeju National University, Jeju 63243, Korea; gaegu1210@jejunu.ac.kr \\ Electric Energy Research Center, Jeju National University, Jeju 63243, Korea; chae@jejunu.ac.kr \\ 3 Department of Electrical Engineering, Jeju National University, Jeju 63243, Korea \\ * Correspondence: ehkim@jejunu.ac.kr; Tel.: +82-64-756-3678
}

Received: 6 October 2020; Accepted: 2 November 2020; Published: 4 November 2020

\begin{abstract}
Steady-state, harmonics, and transient analysis of a power system by using a detailed simulation model is essential to microgrid operation before the installation of new power facilities, because the microgrid, which is a small-scale independent power grid consisting of distributed resources and an energy storage system, has no choice but to include many inverters consisting of switching devices. Accordingly, in the case of an accident in a microgrid system, various power system simulation tools must be used to calculate the fault current for grid protection components. Specifically, Modelling using Power System Computer Aided Design (PSCAD)/Electro-Magnetic Transient Design and Control (EMTDC) can perform detailed modeling of switching devices into each inverter, and Electrical Transient Analyzer Program (ETAP) can design protection relays. From this perspective, this study designed whole protection components in a microgrid system, including the capacity of switching devices for fault ride through a protective relay and the capacity of the circuit breaker. The parameters of an actual microgrid on the San Cristobal Island, Galapagos, were used to make a detailed simulation model in both PSCAD/EMTDC and ETAP. The capacities of the switching devices were estimated by using PSCAD/EMTDC. Additionally, the rated breaking capacities and the setting values of the protective relay were also calculated from the result of an ETAP simulation.
\end{abstract}

Keywords: ETAP; fault current analysis; microgrid; protection system; PSCAD/EMTDC

\section{Introduction}

According to advanced research, computer modeling and power system analysis are very important for the stable operation and management of power systems [1]. Specifically, before connecting a new power facility to a sensitive power system such as a microgrid, detailed analysis using computer simulation must be performed to check normal operation, transient state, harmonics, and dynamic characteristics. As the microgrid is a small-scale independent power grid, which consists of renewable energy sources, such as solar or wind power, with an energy storage system (ESS), a detailed power system analysis should be completed [2,3]. Several inspiring papers, such as "Fault analysis of 380V DC-microgrid" and "An inverter-only supplied microgrid analysis," have analyzed various results on microgrids using power system simulation tools [4-9]. However, there are no papers that design whole protection components of the microgrid using the Power System Computer Aided Design (PSCAD)/Electro-Magnetic Transient Design and Control (EMTDC) and Electrical Transient Analyzer Program (ETAP) programs. In addition, in the event of an accident on the microgrid, the calculation of the fault current requires the use of various simulation tools to improve accuracy. Currently, PSCAD/EMTDC is specialized in various types of AC and DC power facilities, namely PCS simulation studies, including power electronics, subsynchronous resonance, and lightning overvoltage [10-13]. Thus, detailed modeling of the inverter switching device and the conventional 
power system can be performed. ETAP is useful to calculate the fault current, design a protection system, and analyze power system stability [14-17]. With ETAP, unlike PSCAD/EMTDC, it is not possible to model the inverter's switching device in detail, but the advantages of simple modeling of the power system, the result of the accident current calculation, and setting the protective relay in the event of a system accident can be derived within a short time.

This study proposed to design a method of whole protection components in a microgrid system by using various power system simulation programs. First, the simulation models of the microgrid were made using the PSCAD/EMTDC and ETAP programs. In this study, the PSCAD/EMTDC simulation model was focused on inverter facilities, including the topology, filter, and even the controller. The ETAP model was created by using its well-made libraries. Second, the ground and short-circuit fault current values were calculated. Then, the calculation results were compared with each program to improve the accuracy and reliability of the simulation models. Third, the circuit breaker capacities were decided by the worst fault current flowing into the bus at each distributed resources-side, calculated through the ETAP program. Fourth, the capacities of the switching devices in the inverter system were estimated to consider the self-protection sequence and the capable low voltage ride through (LVRT) operation through the PSCAD/EMTDC simulation result in which the maximum fault current flows to the insulated gate bipolar transistors (IGBTs) [18-22]. Finally, the setting values of the protective relays were corrected in consequence of the ETAP simulation results. To verify the effectiveness of the proposed method, the parameters for San Cristobal Island, Galapagos, where the actual average load is about 1.8 MW, were applied to each simulation tool. The example microgrid was installed with distributed resources, including 6.39 MW diesel generators, a 2.095 MWh ESS, 1 MW photovoltaics (PVs), and three $0.8 \mathrm{MW}$ wind turbines. The simulation analysis scenarios assumed that the fault occurred at the zero-crossing point of phase A in normal conditions. This is shown as a single line diagram in Figure 1. The power system of this study operates only two 1.67 MW diesel generators according to the load size, PV generates $1 \mathrm{MW}$ output, and ESS controls PV output fluctuations [23]. In addition, the wind turbine (WT) was operated at only two $800 \mathrm{~kW}$ to prevent light-load operation of diesel generators.

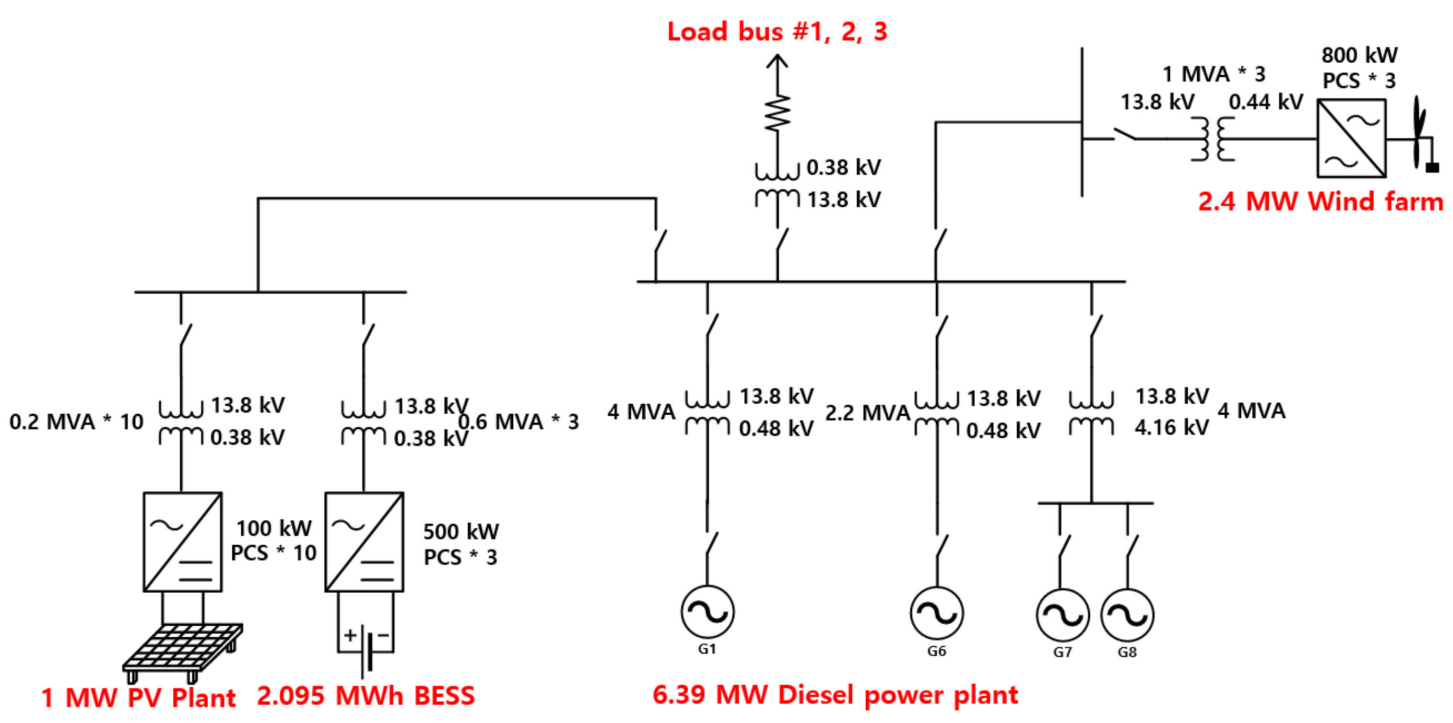

Figure 1. Overview of San Cristobal Island power system.

\section{Protection Theory}

There are many studies on how to protect microgrids [24,25]. In this paper, we focused on two items necessary for microgrid protection. The first is the LVRT control of the inverter. It is a method to prevent drop from the power system by supplying reactive power in consideration of the accident time and voltage reduction rate when low voltage of the system occurs. Therefore, the capacity of the 
inverter's IGBT must be designed in accordance with the LVRT condition. Second, the short-circuit current calculation needs to be considered. In the event of an accident in the power system, not only the inverter, but also the circuit breaker and protection relay must be managed. Accordingly, it is possible to quickly prevent the spread of an accident by the proper breaker capacity and the set value of the protection relay through accurate short-circuit current calculation.

\subsection{LVRT Control Method}

Figure 2 shows the detailed controller of a two-level power conversion system (PCS) model for the PVs, ESS, and WTs. From inverter control theory, the terminal voltage of the two-level inverter in the dq-axis using Park's transformation can be expressed as

$$
\begin{aligned}
& v_{t d}=-L_{i} \frac{d i_{d}}{d t}+\omega L_{i} i_{q}+v_{s d} \\
& v_{t q}=-L_{i} \frac{d i_{q}}{d t}-\omega L_{i} i_{d}+v_{s q}
\end{aligned}
$$

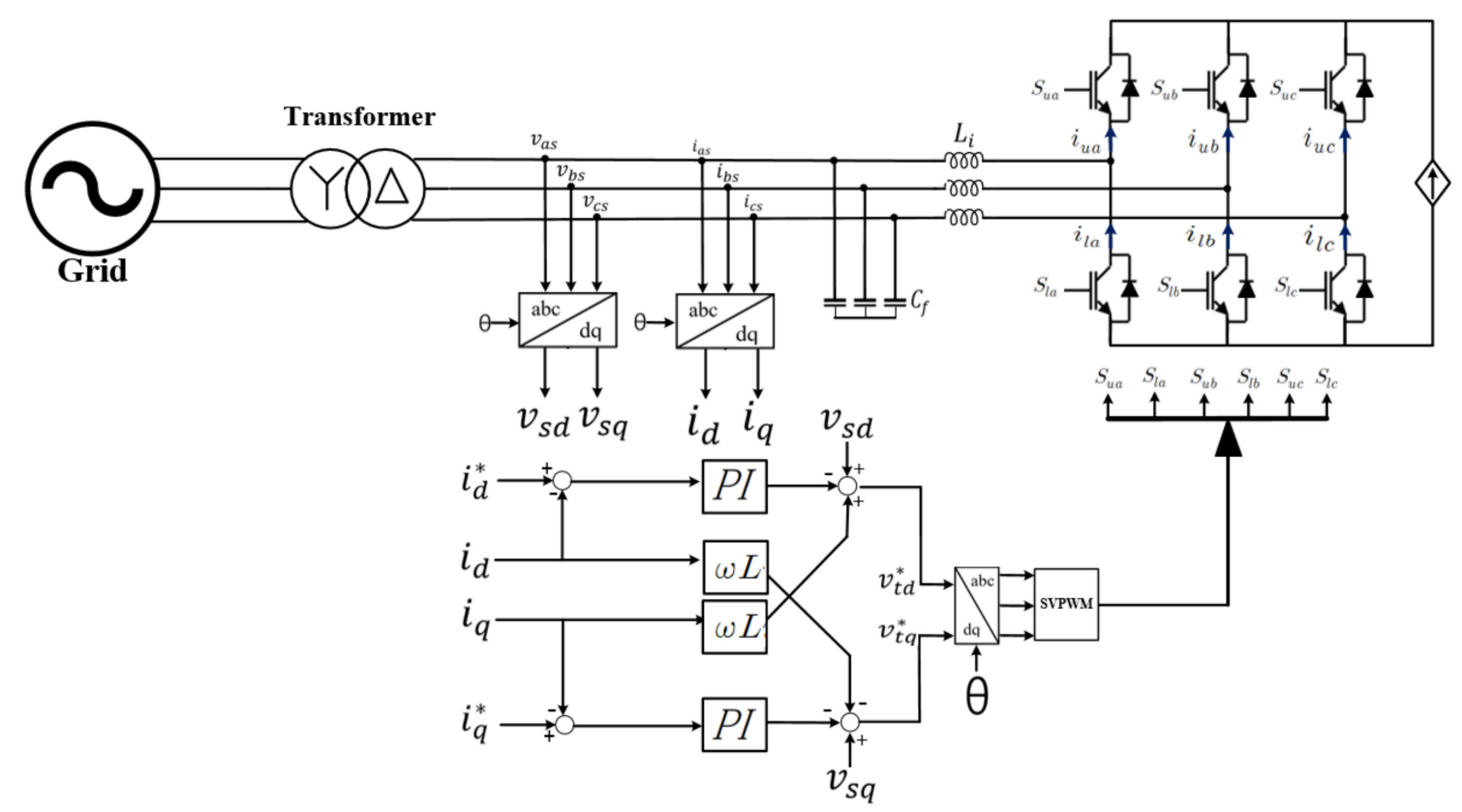

Figure 2. Two-level inverter simulation model.

By using decisions of filter capacity, the gains and bandwidth of the proportional integral (PI) controller were calculated. Then, these values were tuned considering the response of the PCS, such as overshoot, rising time, and so on [26,27]. If the PI controller is used, it can be expressed as

$$
\begin{aligned}
& v_{t d}^{*}=-\left(k_{p}+\frac{k_{i}}{s}\right)\left(i_{d}^{*}-i_{d}\right)+\omega L_{i} i_{q}+v_{d} \\
& v_{t q}^{*}=-\left(k_{p}+\frac{k_{i}}{s}\right)\left(i_{q}^{*}-i_{q}\right)-\omega L_{i} i_{d}+v_{q}
\end{aligned}
$$

In the above equation, $i_{d}^{*}$ and $i_{q}^{*}$ are set to perform current control by using Equations (5) and (6):

$$
Q_{\text {ref }}=\left\{\begin{array}{c}
0\left(0.8 V_{\text {rated }}<\Delta V \leq 0\right) \\
\Delta V \times k\left(0.5 V_{\text {rated }}<\Delta V \leq 0.8 V_{\text {rated }}\right) \\
Q_{\text {max }}\left(0.3 V_{\text {rated }}<\Delta V \leq 0.5 V_{\text {rated }}\right)
\end{array}\right.
$$




$$
\begin{aligned}
& i_{d}^{*}=Q_{r e f} / \frac{3}{2} v_{q} \\
& i_{q}^{*}=P_{r e f} / \frac{3}{2} v_{q}
\end{aligned}
$$

where $i_{d}^{*}$ means that the PCS operates as the unity power factor in a steady state and supports the grid stability by using a LVRT operation in a transient state, as shown in Figure 3. In addition, $\Delta V$ in Equation (5) refers to the error between the line voltage root mean square (RMS) value and the reference line voltage RMS value flowing into each system. If the grid voltage drops below $30 \%$ of the rated voltage because of a severe fault, the PCS will be disconnected from the grid by its self-protection. The $P_{\text {ref }}$ of $i_{q}^{*}$ represents the active power of the connected sources.

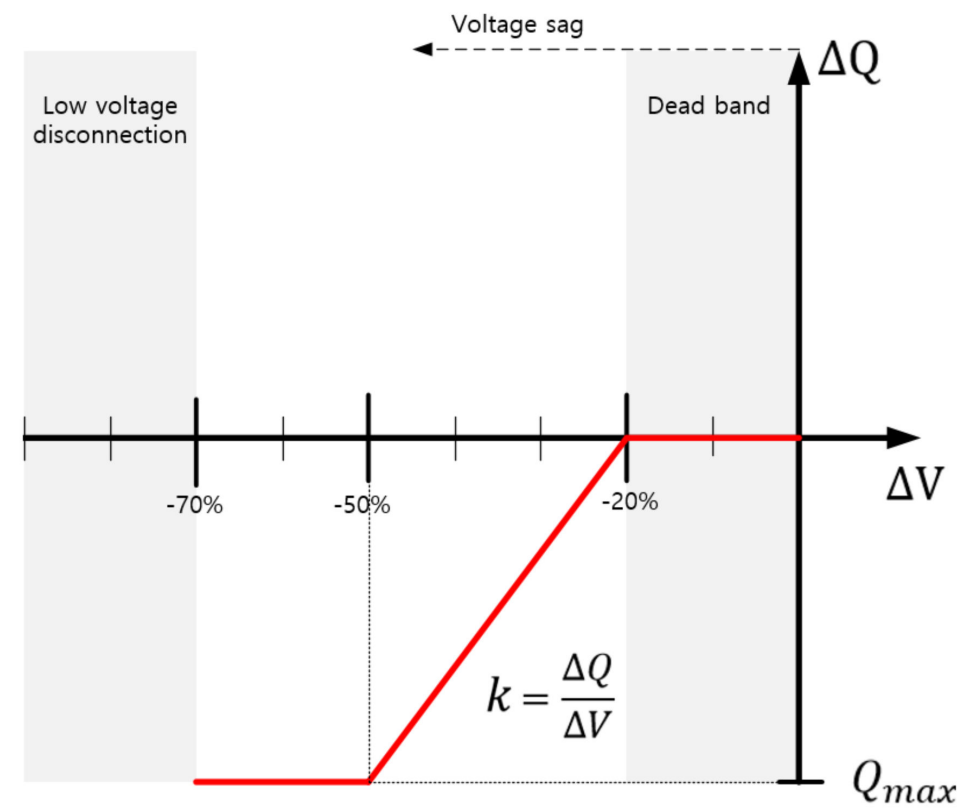

Figure 3. Low-voltage ride-through requirement.

\subsection{Fault Current Calculation}

When an accident occurs in the power system, an asymmetric current flows about the horizontal axis as shown in Figure 4. The fault current expressed in red in Figure 4 includes the symmetrical $\mathrm{AC}$ current that occurred by the rotating machine connected to the power system and the DC current indicated in blue, which is determined according to the $\mathrm{X} / \mathrm{R}$ ratio. In ETAP, according to the International Electrotechnical Commission (IEC) standard, the short-circuit current is calculated as above [28]. $I_{k}$ is the RMS value of the AC symmetrical component of an available short-circuit current applicable at the instant of the short-circuit if the impedance remains at zero time value, which is shown in Equation (8). Voltage factor $c$ is used to adjust the value of the equivalent voltage source for minimum and maximum current calculations according to the nominal voltage and voltage regulation. In Equation (9), $i_{p}$ is the maximum possible instantaneous value of the available short-circuit current; $m$ is a function of the power system $X / R$ ratio at the fault location. Therefore, the initial symmetric short-circuit current and peak short-circuit current can be calculated using the ETAP program.

$$
\begin{gathered}
I_{k}=c U_{n} / \sqrt{3} Z_{e q} \\
i_{p}=\sqrt{2} m I_{k}
\end{gathered}
$$




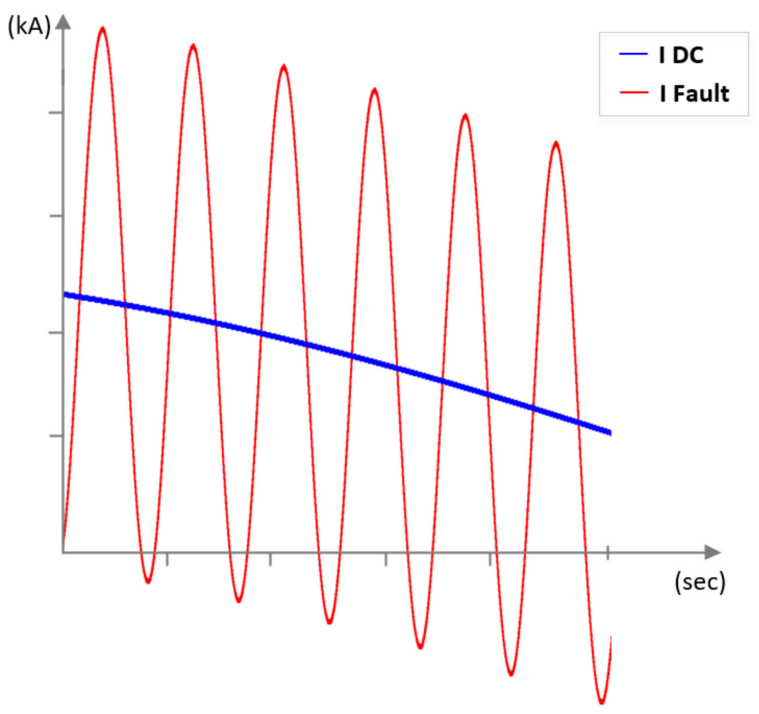

Figure 4. The form of fault current.

\section{Power System Modeling of a Microgrid}

The example power system model of Galapagos' San Cristobal Island was made by using the PSCAD/EMTDC and ETAP programs. The distributed resources of the island consist of a $6.39 \mathrm{MW}$ diesel power plant, $1 \mathrm{MW}$ PV, a 2.095 MWh ESS, and a 2.4 MW wind power plant. In addition, the input parameters in each program were set to match the actual values.

\subsection{Power System Modeling Using PSCAD/EMTDC}

Figure 5 represents the overall PSCAD/EMTDC model of the island. All of the distributed resources, including the diesel generators, PV, ESS, and wind farm, are connected to the same bus in the substation. In addition, there are three load buses, which are linked to the urban area with two lines and the rural area with one line. The real line parameters of the overhead lines and underground cables are used for the simulation model. The 1.8 MW averaged power loads are modeled as a variable load with the actual load data applied.

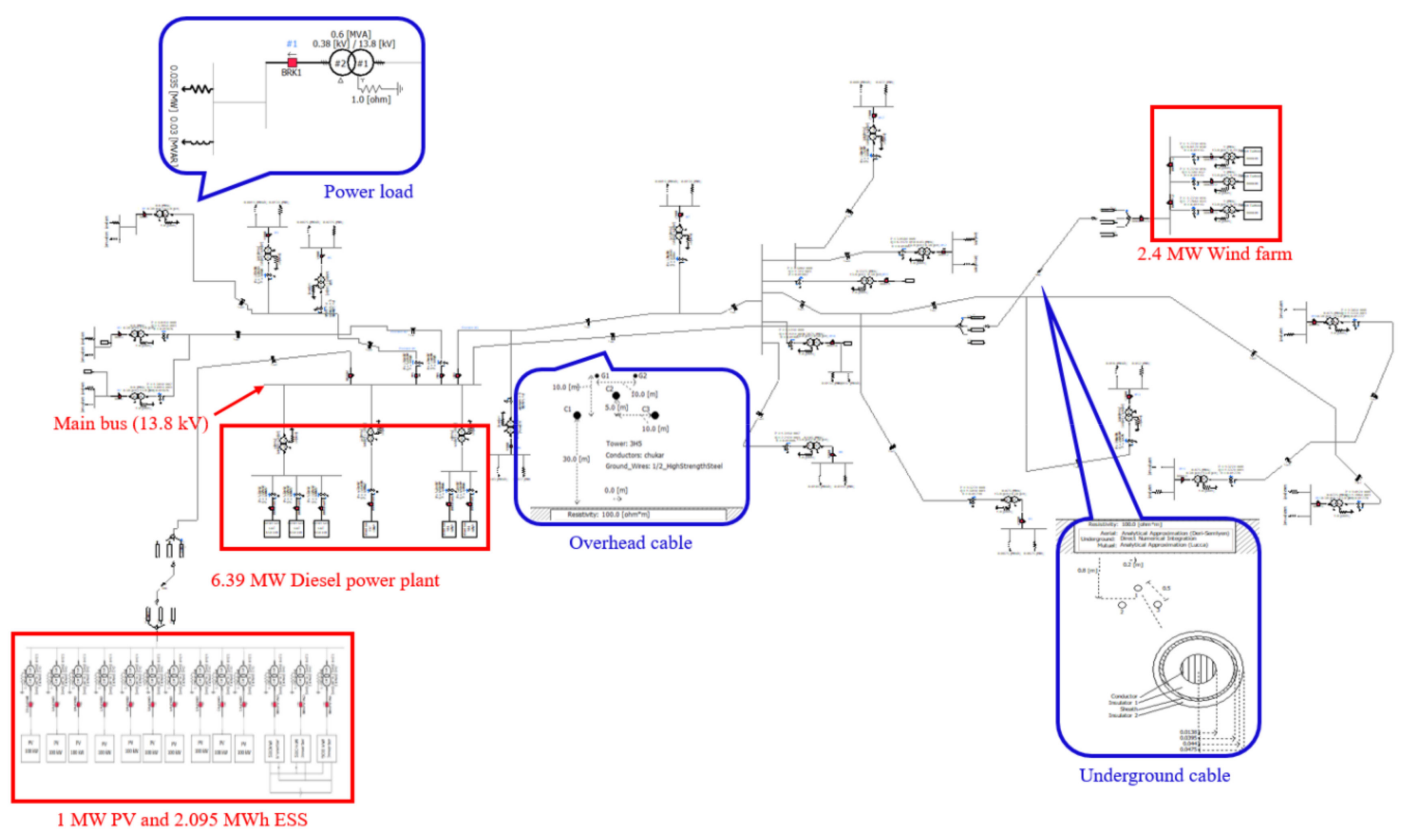

Figure 5. Overall simulation model in PSCAD/EMTDC. 
Figure 6 is an enlarged view of a diesel power plant simulation model. It consists of six generators, each with a different capacity. However, in this study, two 1.67 MW diesel generators were operated, considering the grid conditions. Figure 7 is a detailed model of the $1.67 \mathrm{MW}$ generator in Figure 6. This figure shows the detailed parameters of the engine and synchronous generator, such as the subtransient reactance, transient reactance, and the rated speed of the engine.

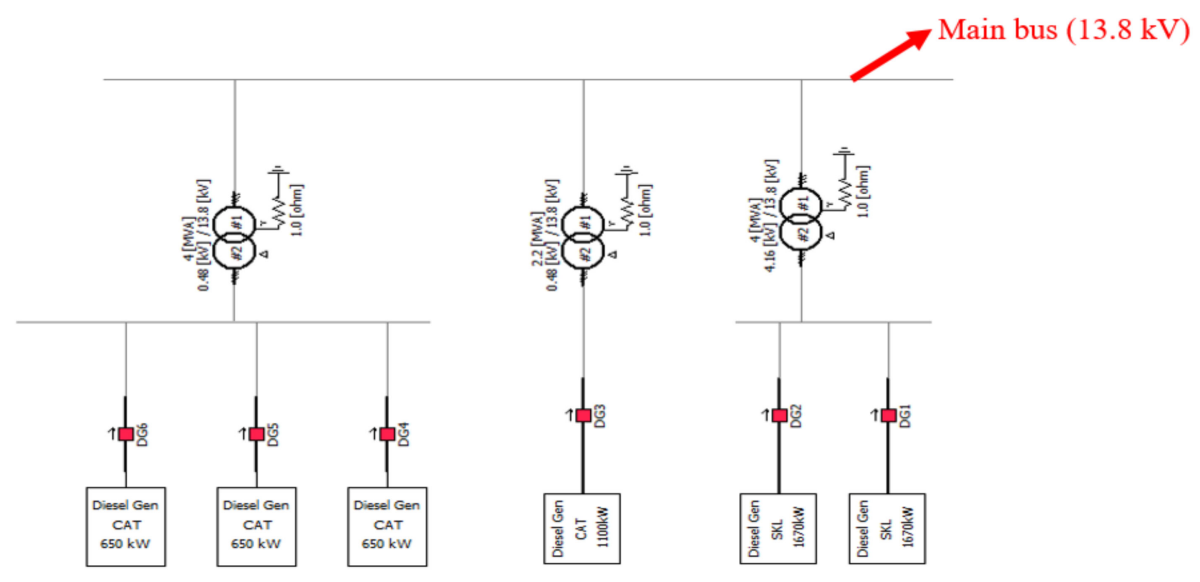

Figure 6. Structure of a diesel power plant model in PSCAD/EMTDC.
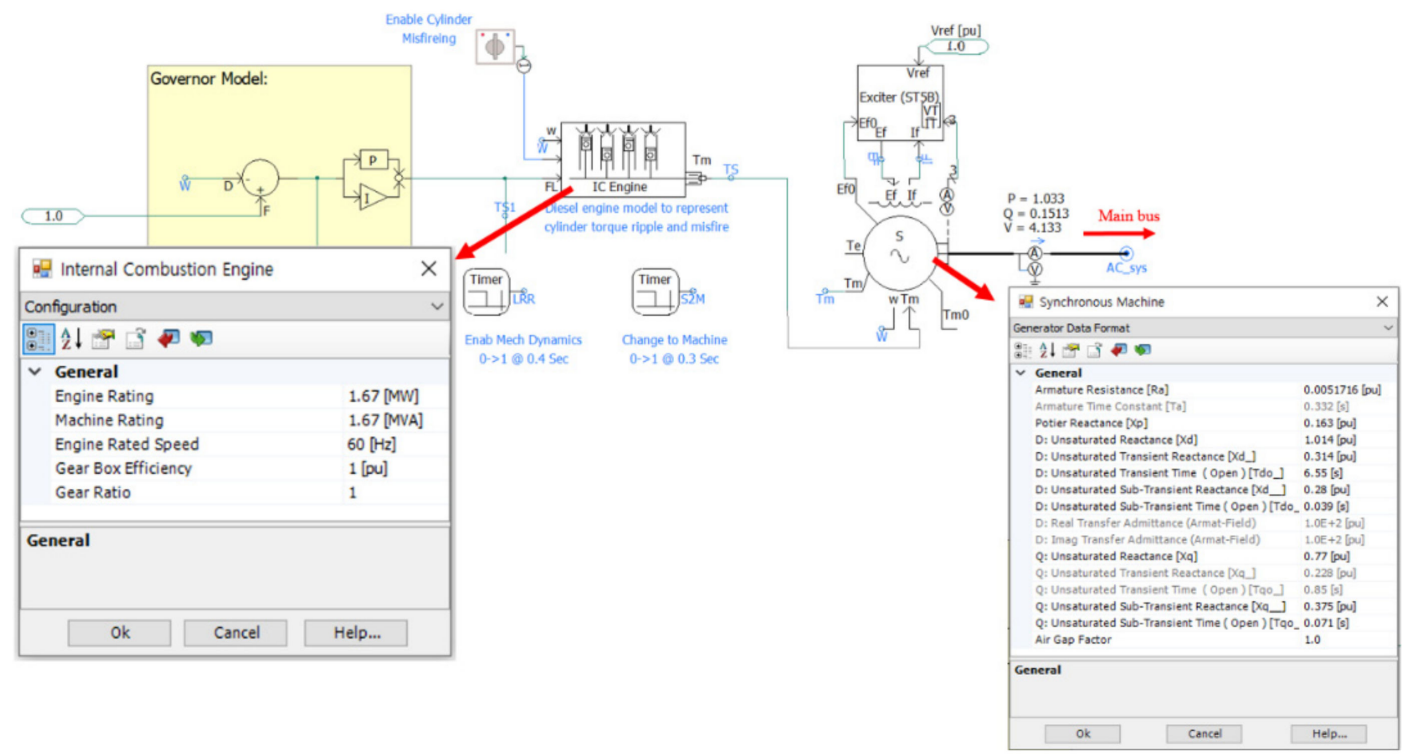

Figure 7. Detailed model of the diesel generator and its parameters.

Figure 8 is a simulation model of a 1 MW PV plant and a 2.095 MWh ESS. Ten $100 \mathrm{~kW}$ PVs are linked separately to ten $100 \mathrm{~kW}$ PCSs. The 2.095 MWh ESS is composed of three $500 \mathrm{~kW}$ PCSs with parallel connections, which are shown enlarged in Figure 9. The battery model of ESS uses the library provided by PSCAD/EMTDC, as indicated by the blue box. The ESS plays a role as the PV output power controller as it does with the actual operation. The simulation model of the $2.4 \mathrm{MW}$ wind farm is shown in Figure 10. It is composed of three $800 \mathrm{~kW}$ PCSs. The actual wind power generator is of PMSG (permanent magnet synchronous generator) type, and it is equivalent to a voltage source inverter, as shown in Figure 2. In this study, the wind farm is operated as a curtailed output power to prevent the light operation of diesel generators. 


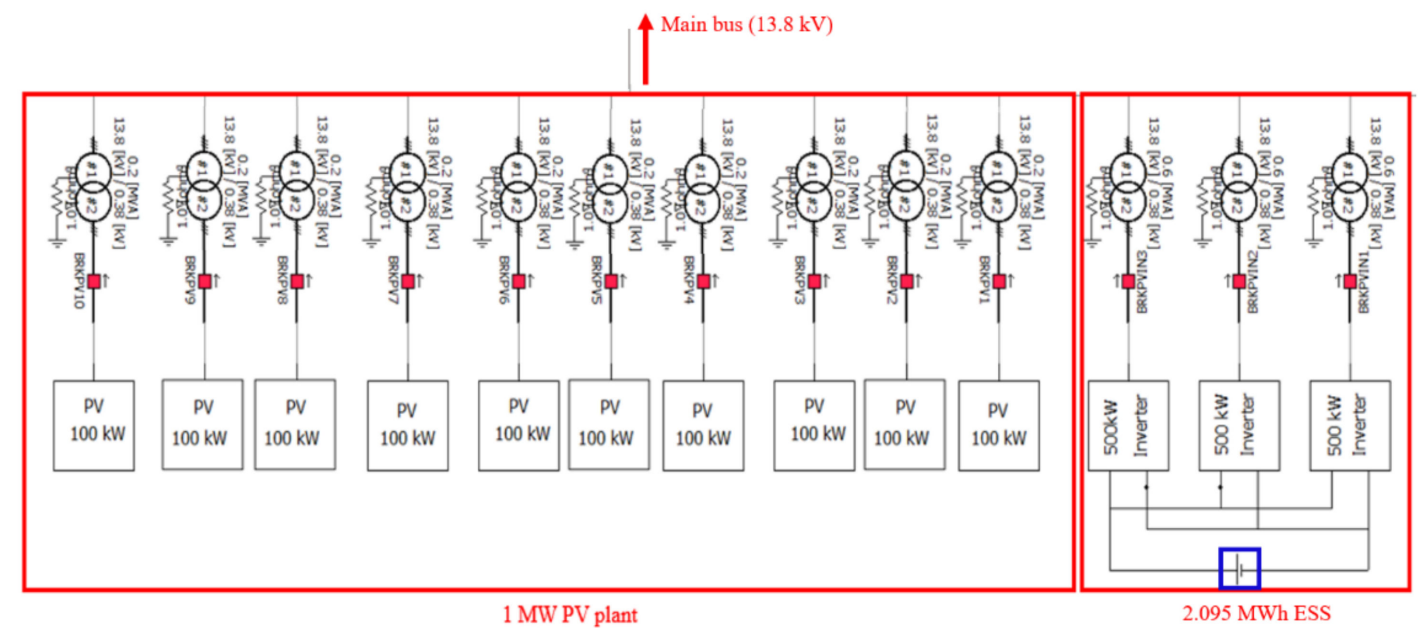

Figure 8. Photovoltaic (PV) plant and energy storage system (ESS) simulation models in PSCAD/EMTDC.

Main bus $(13.8 \mathrm{kV})$
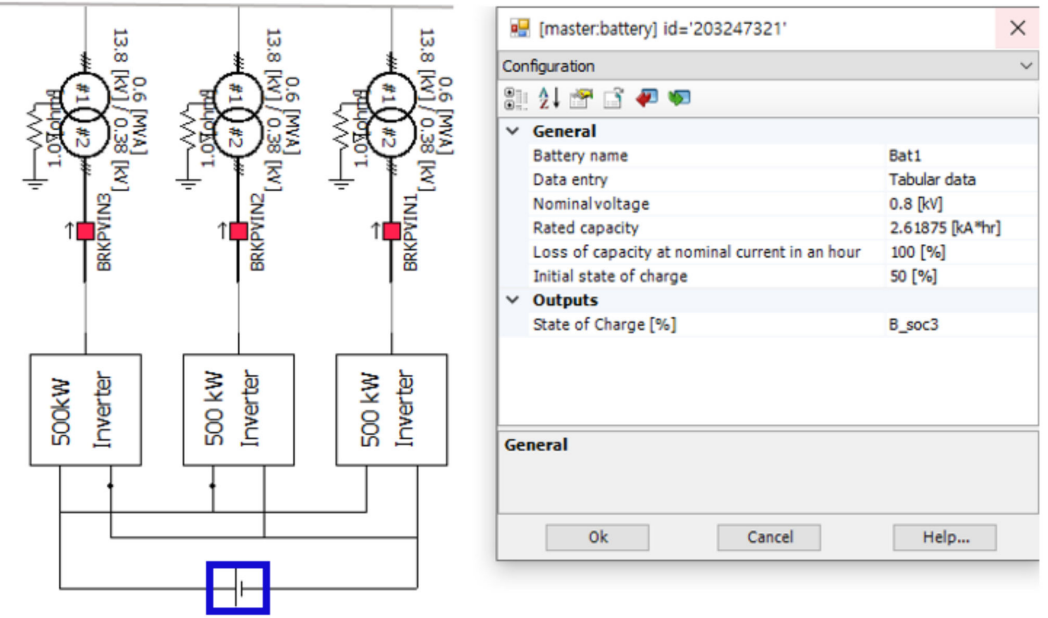

Figure 9. ESS model and battery model parameters in PSCAD/EMTDC.

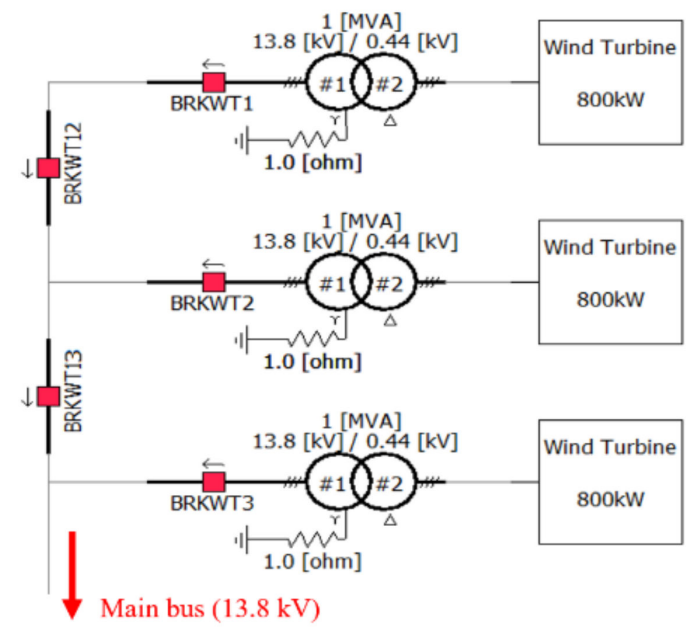

Figure 10. Wind farm simulation model in PSCAD/EMTDC. 
In this paper, we assume the worst situation considering the light load operation of the diesel generator. Therefore, for the situation of $2.7 \mathrm{MW}$ of power load, the output of the 1.6 MW diesel generator is operated at the output of $30 \%$, which is the limit of light load operation. Accordingly, the diesel generator is operated at $0.7 \mathrm{MW}$, output power of the PV inverter is $1 \mathrm{MW}$, and output power of the WT inverter is $1 \mathrm{MW}$. In the case of ESS, because the PV maintains its rating, it already regulates the output fluctuation of PV. Table 1 represents the detailed parameters for the PCS controllers.

Table 1. Detailed parameters for the power conversion systems (PCSs).

\begin{tabular}{ccc}
\hline & Items & Values \\
\hline \multirow{2}{*}{ Common parameters } & Grid frequency & $60 \mathrm{~Hz}$ \\
\cline { 2 - 3 } & Primary side transformer voltage & $13.8 \mathrm{kV}$ \\
\hline & Secondary side transformer voltage & $0.38 \mathrm{kV}$ \\
Rated converter capacity & $100 \mathrm{~kW}$ \\
FV & Filter inductance & $0.89 \mathrm{mH}$ \\
& Filter capacitance & $90 \mathrm{uF}$ \\
Switching frequency & $5000 \mathrm{~Hz}$ \\
Controller bandwidth & $2000 \mathrm{rad} / \mathrm{s}$ \\
DC link voltage & $0.8 \mathrm{kV}$ \\
\hline ESS & $0.38 \mathrm{kV}$ \\
& Secondary side transformer voltage & $500 \mathrm{~kW}$ \\
Rated converter capacity & $0.36 \mathrm{mH}$ \\
Filter inductance & $459 \mathrm{uF}$ \\
Filter capacitance & $2500 \mathrm{~Hz}$ \\
Switching frequency & $1000 \mathrm{rad} / \mathrm{s}$ \\
& Controller bandwidth & $0.8 \mathrm{kV}$ \\
\hline DC link voltage & $0.44 \mathrm{kV}$ \\
& Secondary side transformer voltage & $800 \mathrm{~kW}$ \\
Rated converter capacity & $0.22 \mathrm{mH}$ \\
Find turbine inductance & $734 \mathrm{uF}$ \\
& Filter capacitance & $2500 \mathrm{~Hz}$ \\
& Switching frequency & $1000 \mathrm{rad} / \mathrm{s}$ \\
& Controller bandwidth & $1 \mathrm{kV}$ \\
\hline DC link voltage &
\end{tabular}

\subsection{Power System Modeling Using ETAP}

Figure 11 shows the modeling results using the ETAP program. The capacity of the distributed power source is modeled in the same way as with PSCAD/EMTDC. Unlike PSCAD/EMTDC, the equivalent line is set to a calculated line parameter that is based on the actual line length. In addition, it is modeled using breakers and relays provided by ETAP, as shown in the blue box, to derive the set values of the breakers and protective relays.

In ETAP, detailed generator parameters can be set, as shown in Figure 12. The generator's rated value, impedance, and dynamic model are set to match the actual parameters.

Figure 13 is a simulation model of the ESS. Three $500 \mathrm{~kW}$ PCSs are connected in parallel, and the detailed parameters are shown on the right side of the figure. In addition, 34 batteries in one rack, each with a capacity of $68.476 \mathrm{kWh}$, are connected, resulting in a total capacity of $2.095 \mathrm{MWh}$.

The detailed parameters and structure of the $100 \mathrm{~kW}$ PCSs are the same as the setting values on the right side of Figure 14 .

Figure 15 shows the result of modeling a wind farm composed of three $800 \mathrm{~kW}$ units. The rated value of the wind power generator can be set through the parameters on the left side of Figure 16, and the cut-in speed, cut-out speed, power coefficient, etc., of the wind power generator were designed according to the characteristics of the actual wind power generator. 


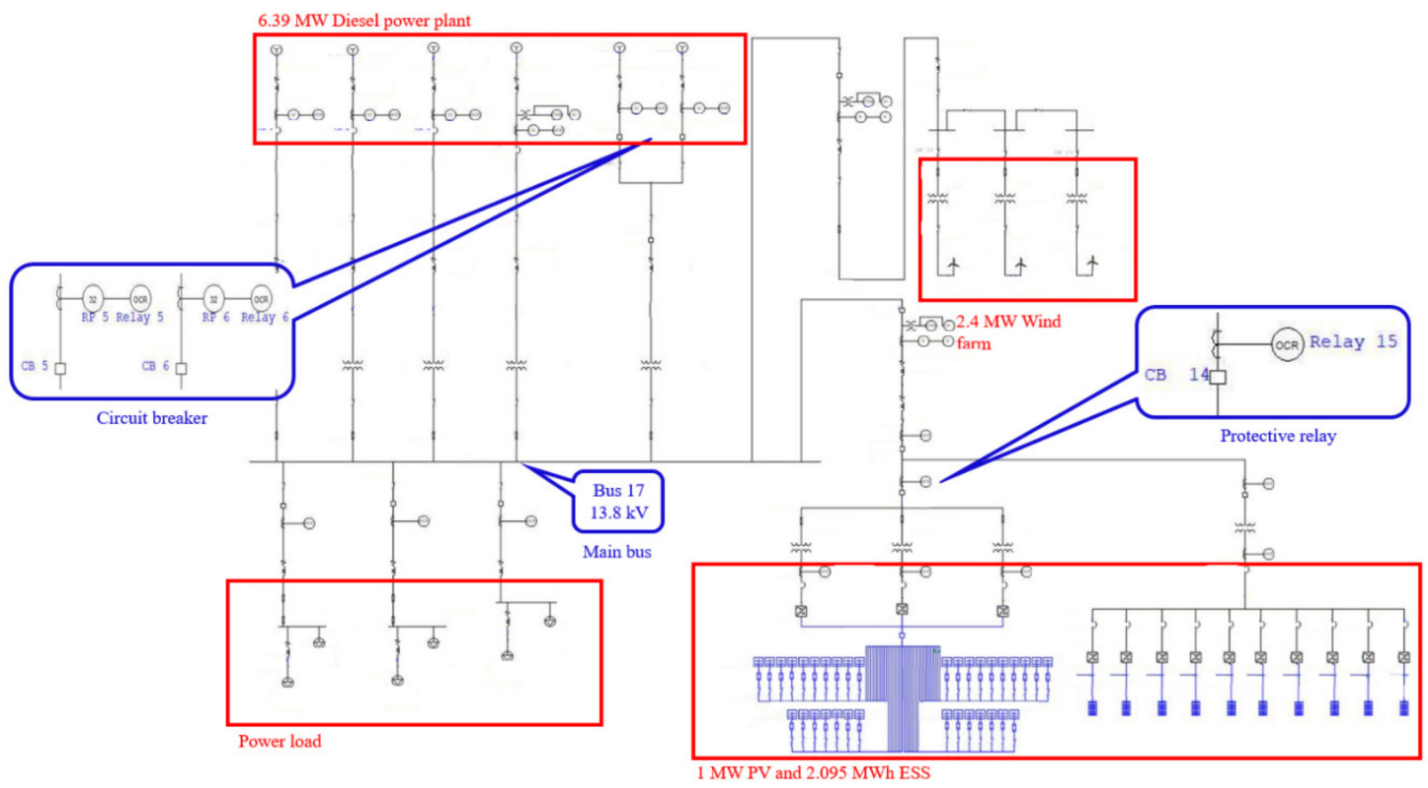

Figure 11. Overall simulation model in ETAP.
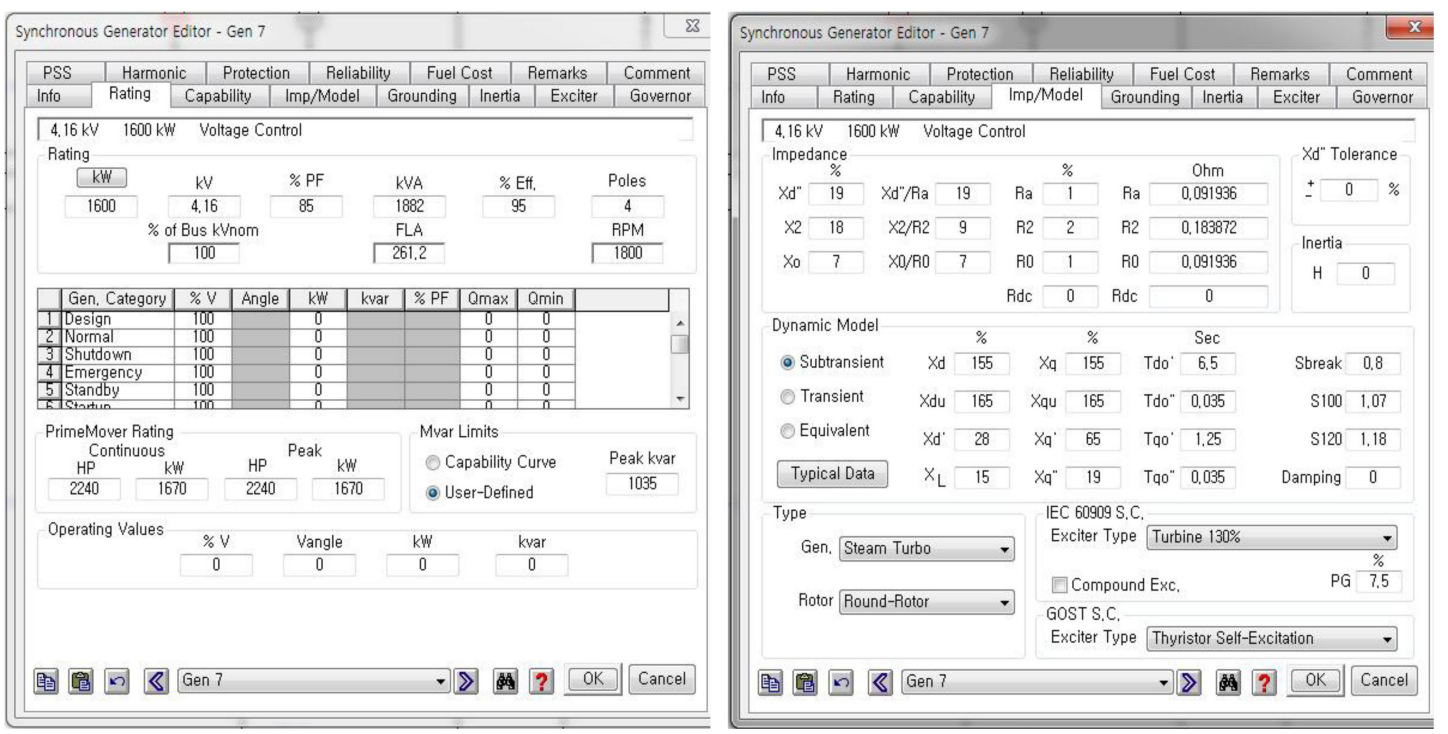

Figure 12. The 1.67 MW diesel generator parameters in ETAP.

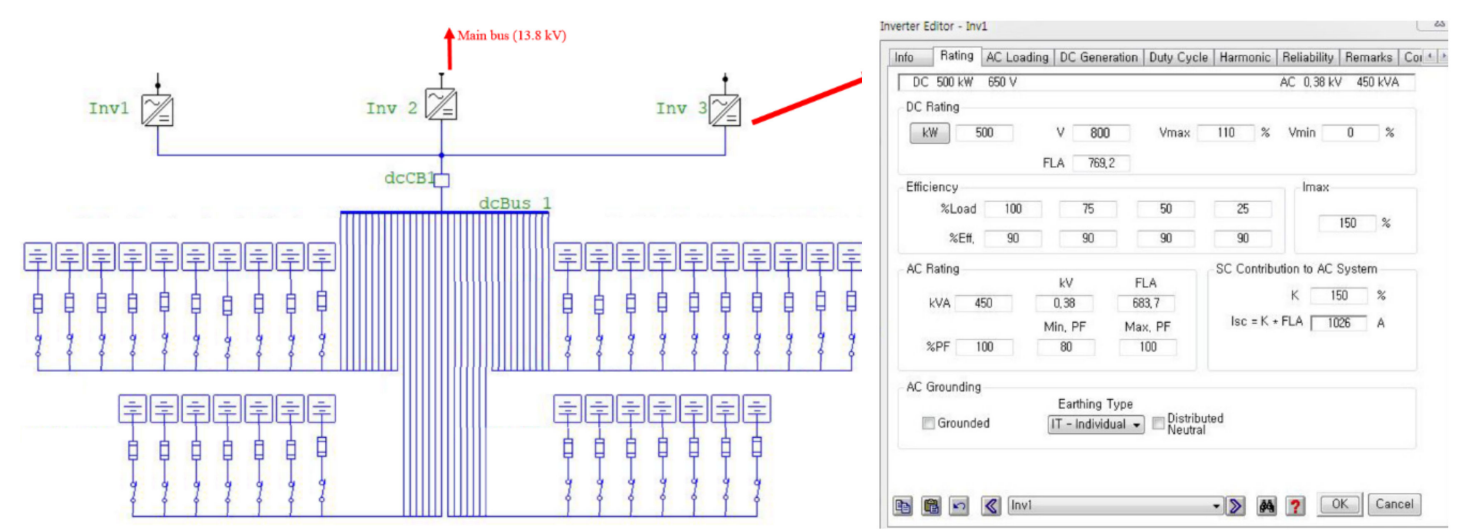

Figure 13. ESS simulation model. 

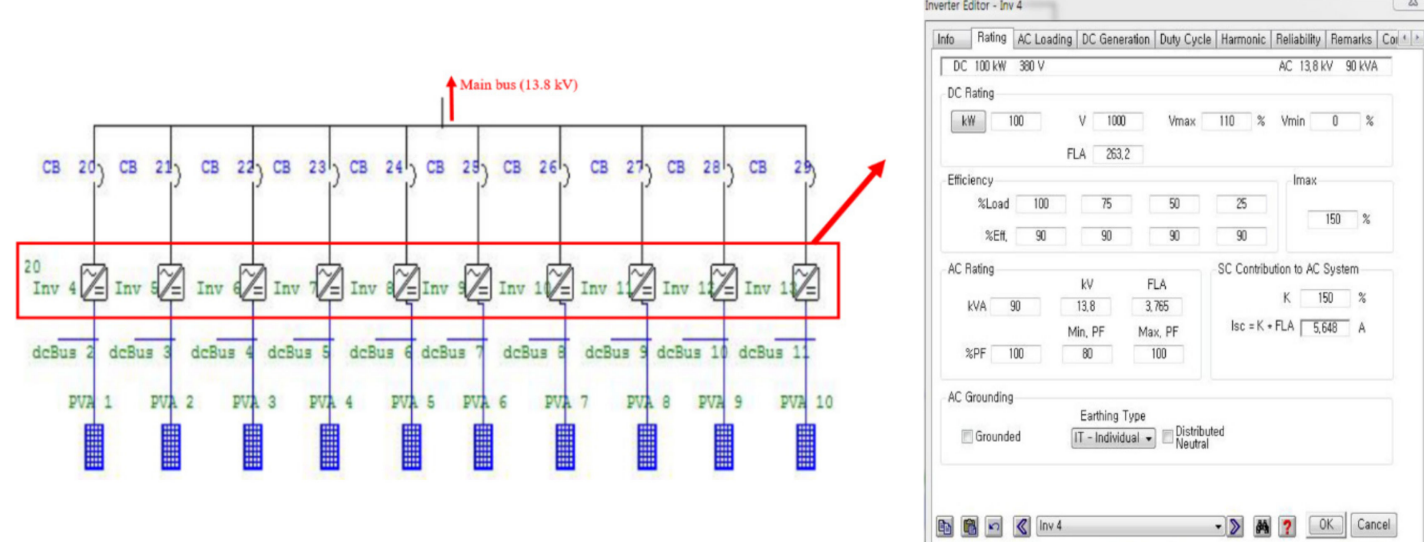

Figure 14. PV simulation model.

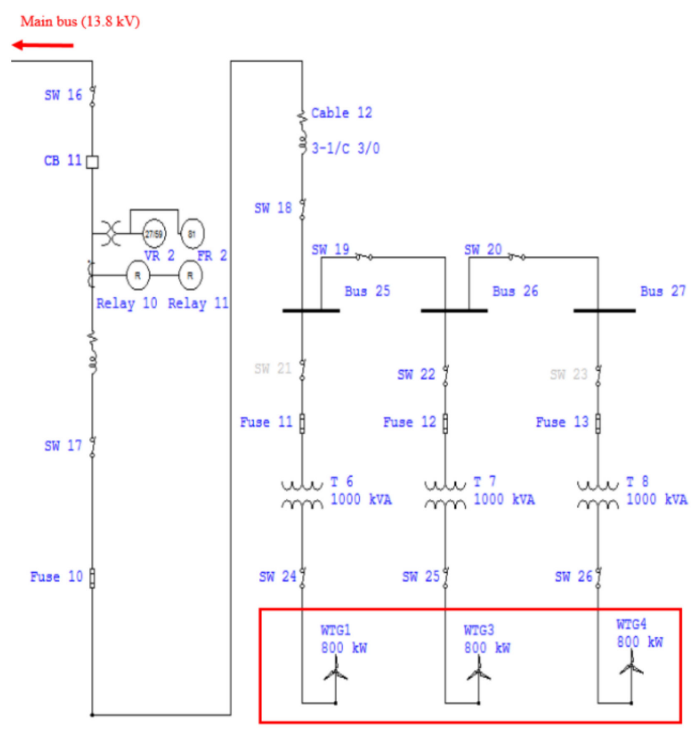

Figure 15. Wind farm simulation model.
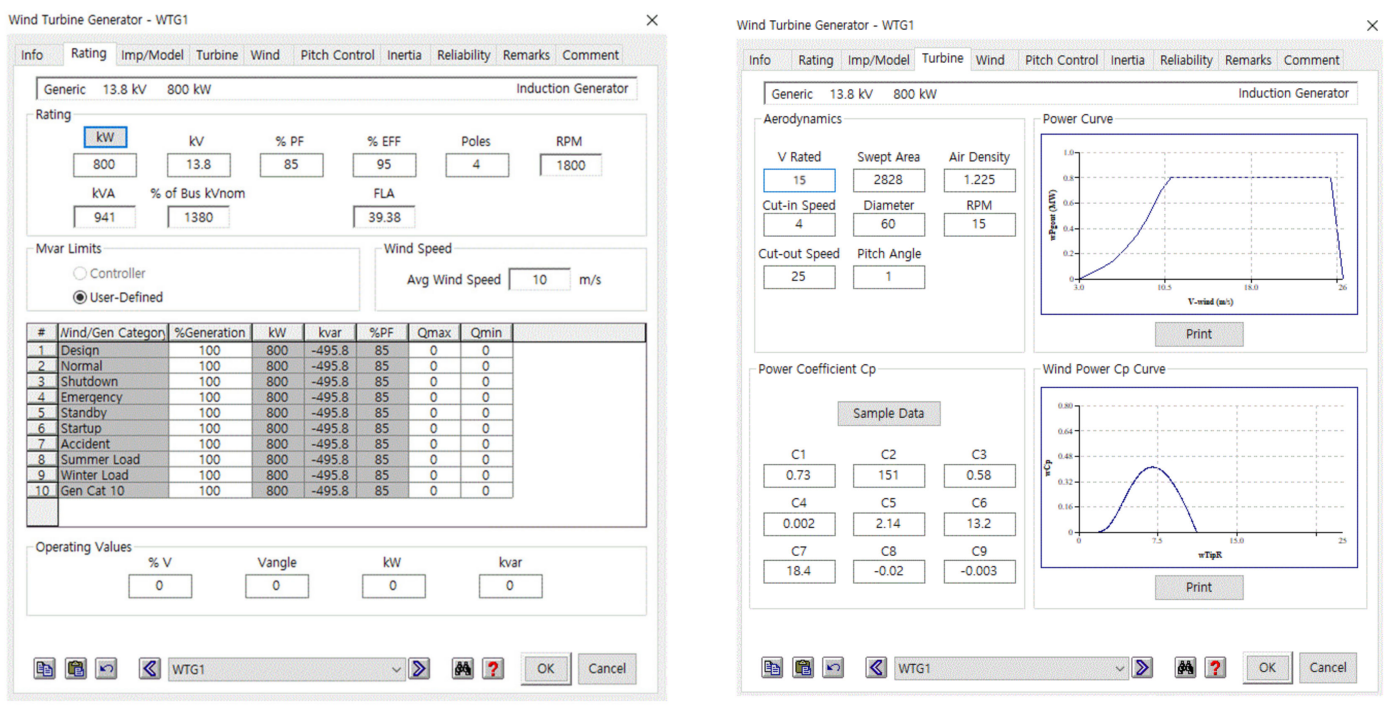

Figure 16. The $800 \mathrm{~kW}$ wind turbine generator parameters. 


\section{Simulation Results}

\subsection{Scenario 1-Ground Fault Accident of Main Power Plant Bus (13.8 kV)}

\subsubsection{Using PSCAD/EMTDC}

In order to confirm the result of the system accident through PSCAD/EMTDC, it is assumed that a single line ground fault occurred in about $5 \mathrm{~s}$. Figure 17a shows the three-phase instantaneous voltage of the main bus and Figure $17 \mathrm{~b}$ represents the three-phase instantaneous current of the main bus. It can be seen that the voltage of phase A becomes $0 \mathrm{~V}$ through the instantaneous three-phase voltage in Figure 17a. The maximum value of the ground fault current is about $2.5 \mathrm{kA}$.

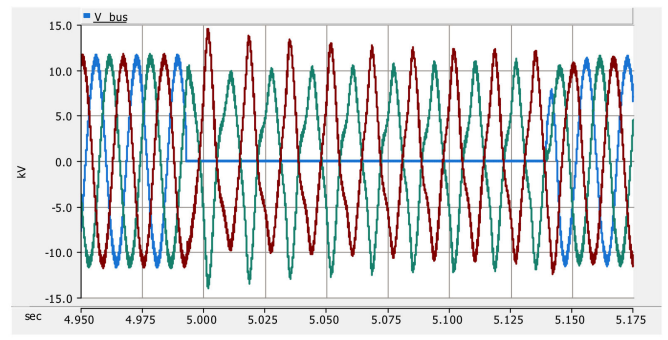

(a)

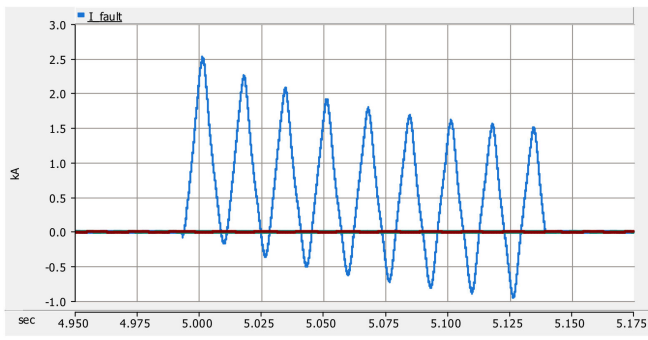

(b)

Figure 17. Simulation results of scenario 1: (a) instantaneous three-phase voltage of main bus and (b) instantaneous three-phase current of main bus.

Figure 18a shows the active and reactive power values of a $1 \mathrm{MW} \mathrm{PV}$ plant. In the case of an accident, the active power value at the top of the figure is controlled to $0 \mathrm{MW}$ and the reactive power value is about $0.2 \mathrm{MVAr}$, depending on the LVRT. In addition, Figure $18 \mathrm{~b}$ shows the current values of the upper IGBT and the lower IGBT of the inverter, and it can be confirmed that a maximum current of $0.65 \mathrm{kA}$ occurs. The ESS PCS and wind farm's PCS shown in Figures 19 and 20 also perform active and reactive power control in the same way as the PV PCS, and a current of up to about $0.7 \mathrm{kA}$ flows into the IGBT devices of the $500 \mathrm{~kW}$ PCS for the ESS. Figure $20 \mathrm{~b}$ shows that up to about $2.5 \mathrm{kA}$ flows into the IGBT devices of the $800 \mathrm{~kW}$ PCS for the wind turbines. The effective power shown in Figures 18a, 19a and $20 \mathrm{a}$ is designed to be controlled by $0 \mathrm{MW}$ in the event of an accident, but not controlled by $0 \mathrm{MW}$ in a short period of time due to a transient state, and this energy is consumed by DC choppers [29,30].

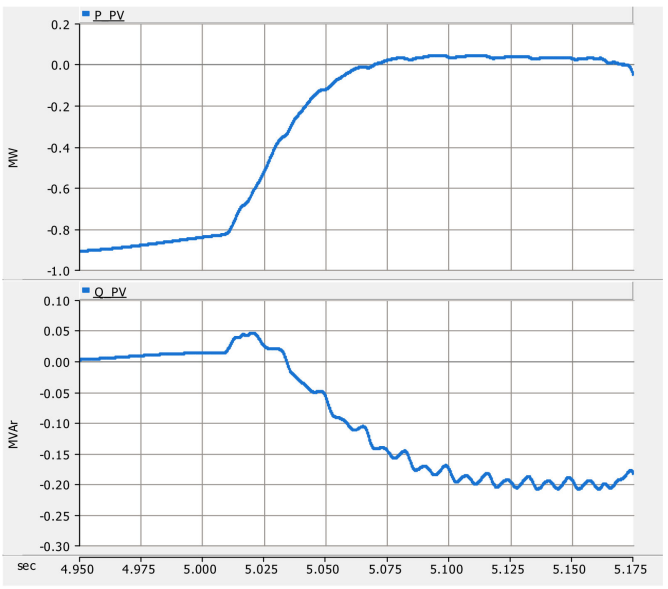

(a)

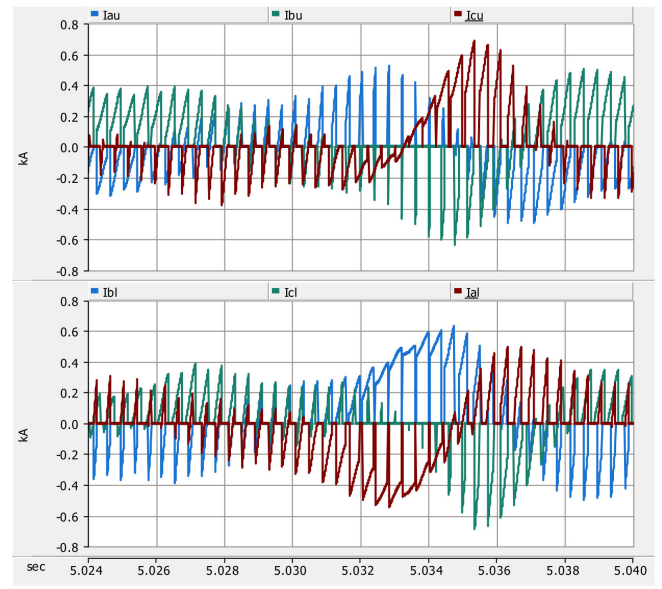

(b)

Figure 18. Simulation results of scenario 1: (a) $1 \mathrm{MW}$ PV plant (top: active power; bottom: reactive power) and (b) $100 \mathrm{~kW}$ PCS (top: current of upper insulated gate bipolar transistor (IGBT); bottom: current of lower IGBT). 


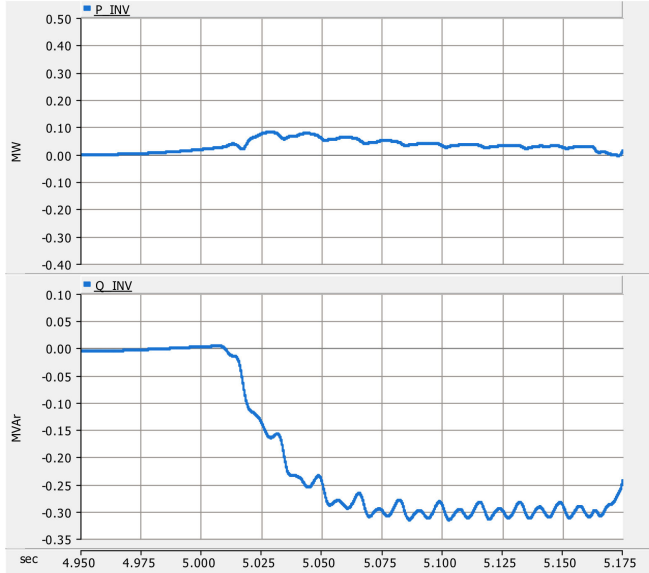

(a)

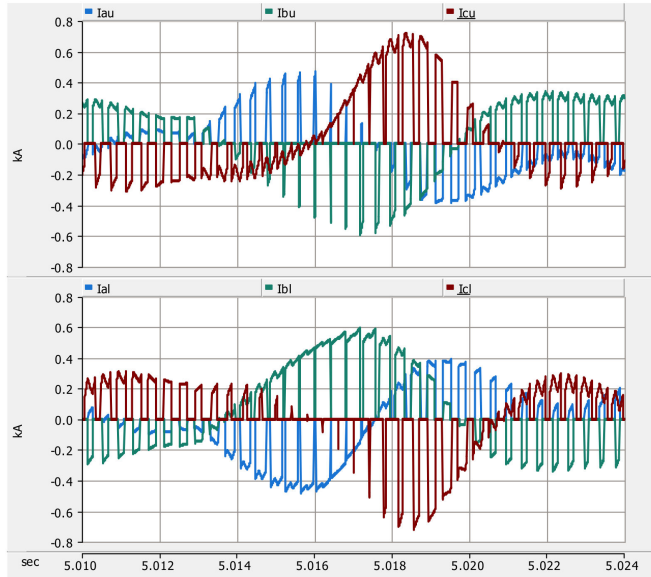

(b)

Figure 19. Simulation results of scenario 1: (a) 1.5 MW PCS of ESS (top: active power; bottom: reactive power) and (b) $500 \mathrm{~kW}$ PCS (top: upper current of IGBT; bottom: lower current of IGBT).

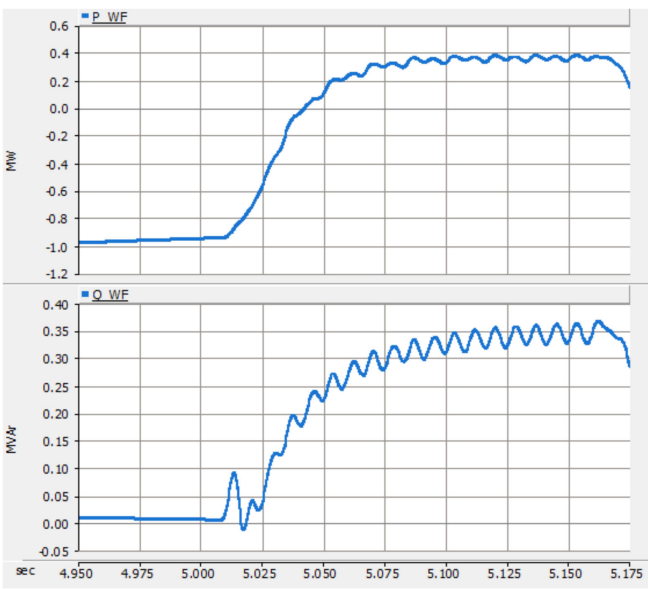

(a)

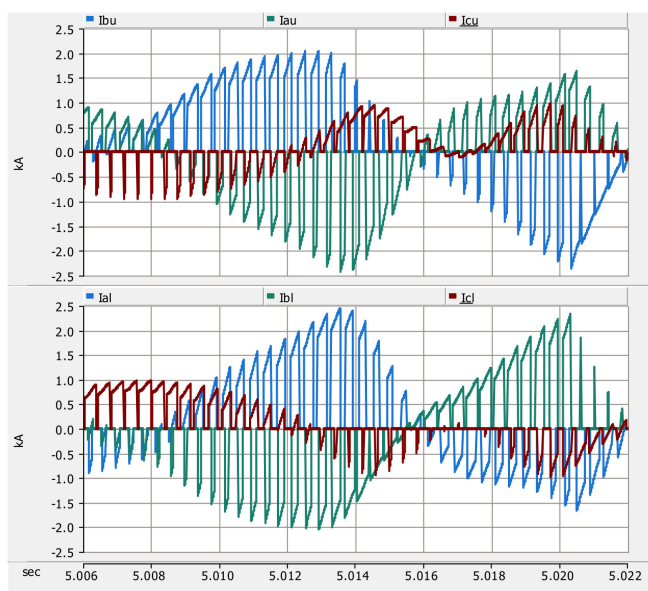

(b)

Figure 20. Simulation results of scenario 1: (a) 2.4 MW PCS of wind farm (top: active power; bottom: reactive power) and (b) $800 \mathrm{~kW}$ PCS (top: upper current of IGBT; bottom: lower current of IGBT).

\subsubsection{Using ETAP}

Figure 21 shows the result of the analysis of the magnitude of the accident current in the event of a ground fault in the power system through ETAP. The magnitude of the accident current flowing into the distributed power and load can be known, but only the magnitude of the accident current of the main bus of the power plant is enlarged, compared with the result value of PSCAD/EMTDC. In ETAP, it can be confirmed that the accident current is $2.27 \mathrm{kA}$, which indicates that there is an error of about $0.23 \mathrm{kA}$ with PSCAD/EMTDC.

\subsection{Scenario 2-Three-Phase Fault Accident of Main Power Plant Bus (13.8 kV)}

\subsubsection{Using PSCAD/EMTDC}

In scenario 2, a three-phase short-circuit accident is assumed at about $5 \mathrm{~s}$. Figure 22a shows the three-phase instantaneous voltage of the main bus, and Figure 22b shows the three-phase instantaneous current on the side of the main bus. It can be seen that a three-phase short-circuit accident occurs because the voltage on the abc-phase when the accident occurs is $0 \mathrm{~V}$. At this time, the maximum value of the short-circuit current is about $1.8 \mathrm{kA}$. 


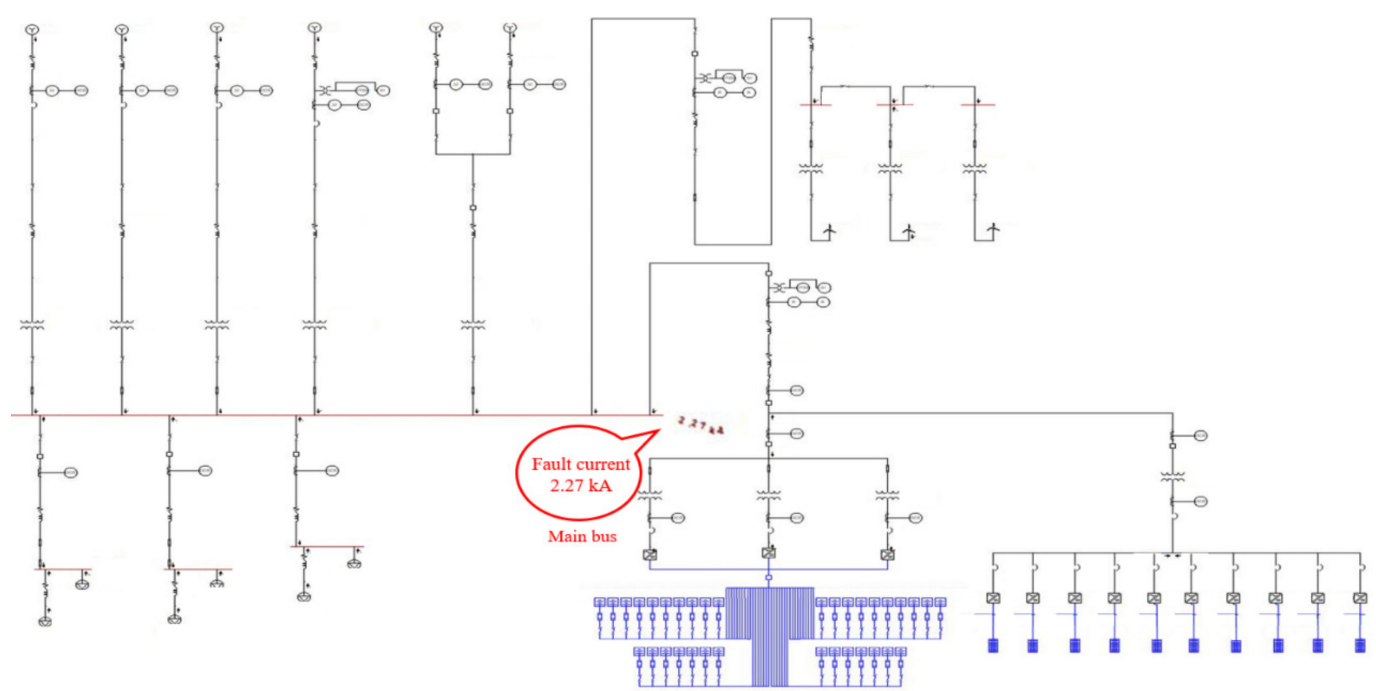

Figure 21. Simulation results of scenario 1: single line ground fault current calculation using ETAP.

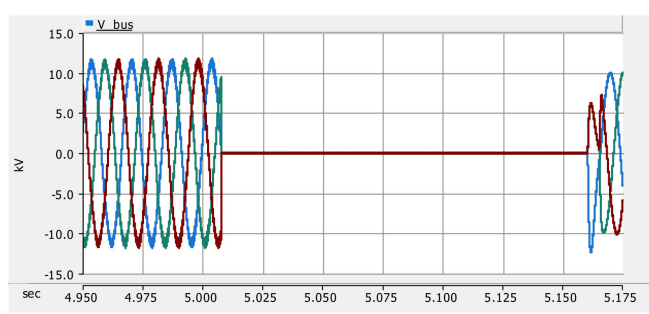

(a)

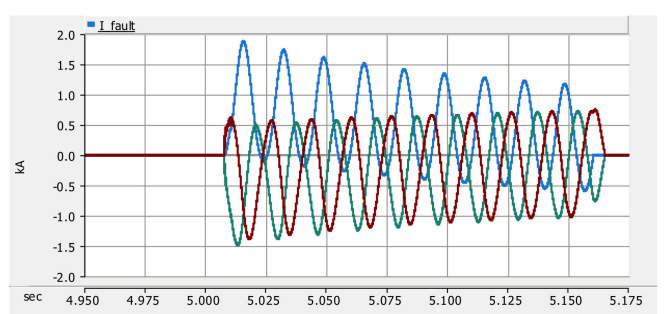

(b)

Figure 22. Simulation results of scenario 2: (a) instantaneous three-phase voltage of main bus and (b) instantaneous three-phase current of main bus.

Figure 23a shows the active and reactive power values of the $100 \mathrm{~kW}$ PCS of PV, and Figure 23b shows the amount of current flowing into the upper and lower IGBTs of the PCS. In contrary to the single line ground fault, when a three-phase short-circuit occurs, the rated voltage drops below $30 \%$ and the PCS is cut off from the grid by its self-protection. Therefore, it can be seen from Figure 23a that the reactive power is continuously $0 \mathrm{MW}$ and $0 \mathrm{MVAr}$, and Figure 23b shows that the IGBT switching operation also stops.

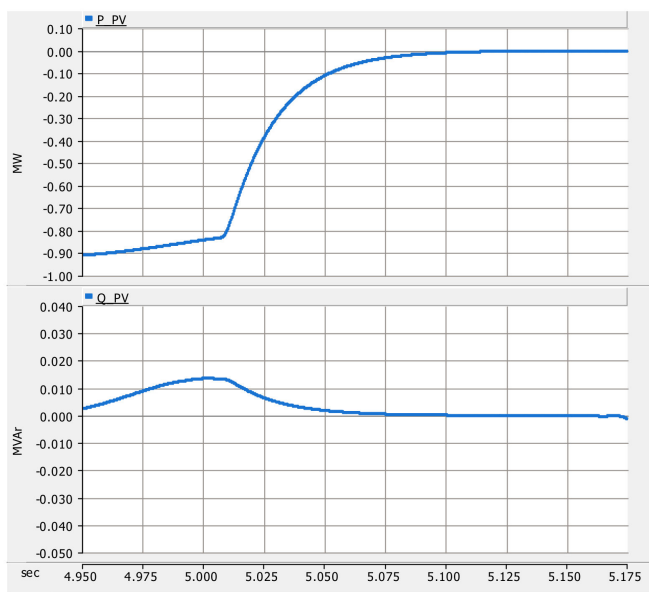

(a)

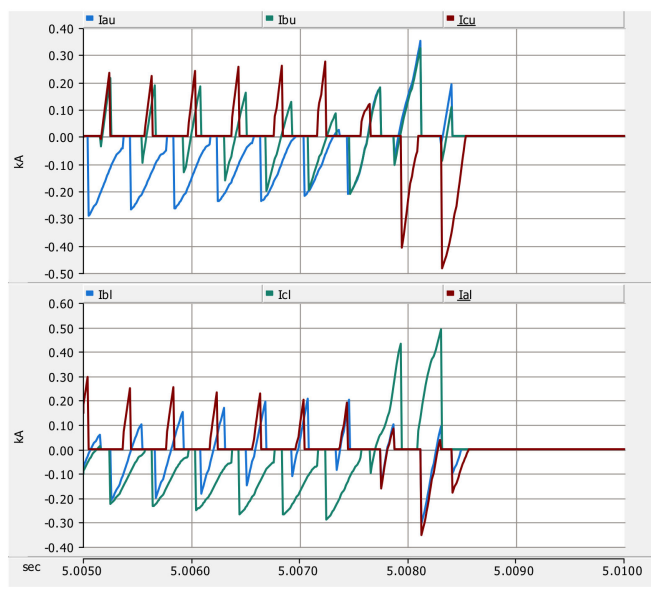

(b)

Figure 23. Simulation results of scenario 2: (a) 1 MW PV plant (top: active power; bottom: reactive power) and (b) $100 \mathrm{~kW}$ PCS (top: current of upper IGBT; bottom: current of lower IGBT). 
It can be seen from Figures 24 and 25 that the ESS's PCS and the wind farm's PCS also stop the active and reactive power control and stop the IGBT switching operation in the same way as the PV's PCS results above.

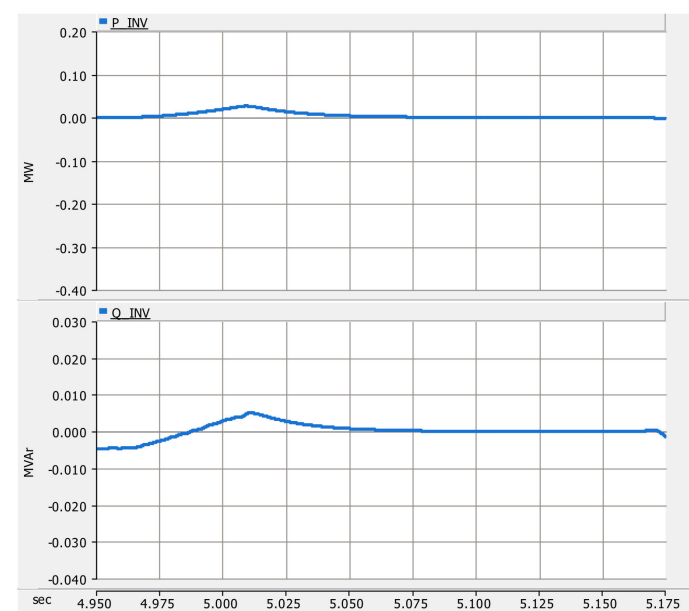

(a)

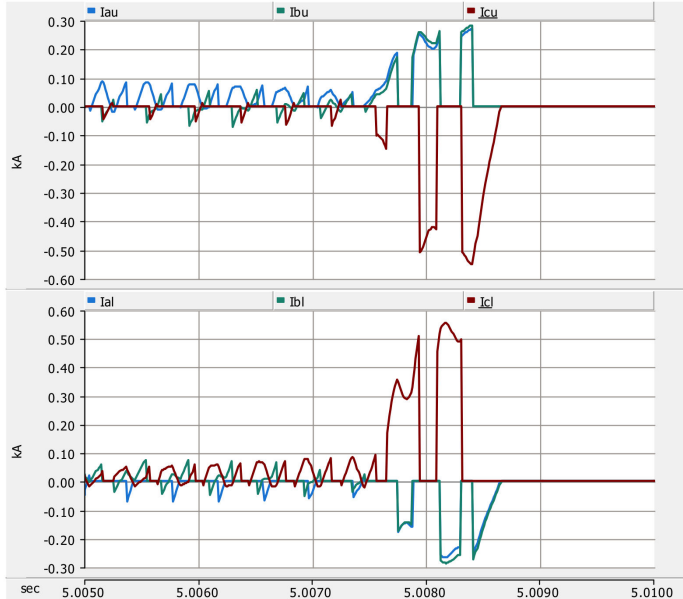

(b)

Figure 24. Simulation results of scenario 2: (a) 1.5 MW PCS of ESS (top: active power; bottom: reactive power) and (b) $500 \mathrm{~kW}$ PCS (top: upper current of IGBT; bottom: lower current of IGBT).

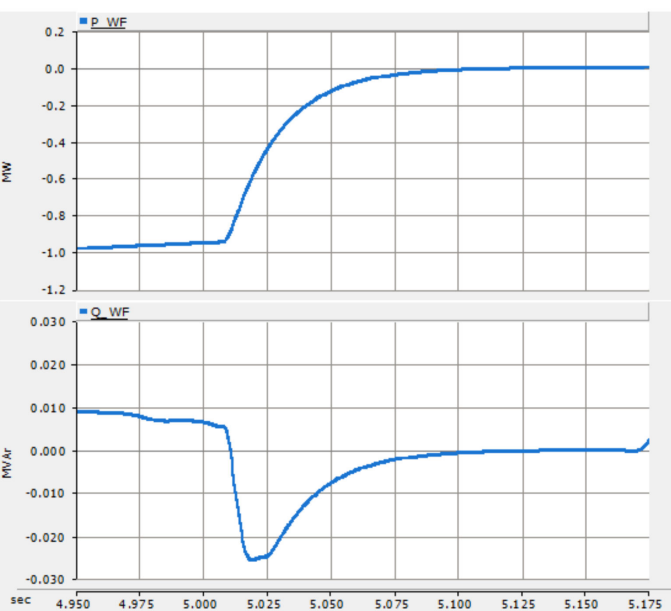

(a)

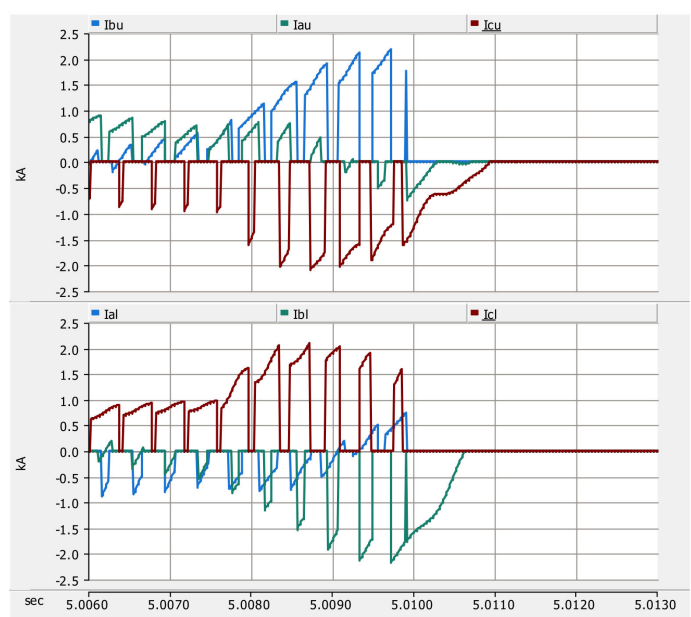

(b)

Figure 25. Simulation results of scenario 2: (a) 2.4 MW PCS of wind farm (top: active power; bottom: reactive power) and (b) $800 \mathrm{~kW}$ PCS (top: upper current of IGBT; bottom: lower current of IGBT).

\subsubsection{Using ETAP}

Figure 26 shows the analysis result indicating the magnitude of the accident current when a three-phase short-circuit accident occurs in the power system through ETAP. The magnitude of the accident current of the main bus of the power plant is $1.7 \mathrm{kA}$, and it can be seen that there is an error of about $0.1 \mathrm{kA}$ with PSCAD/EMTDC. 


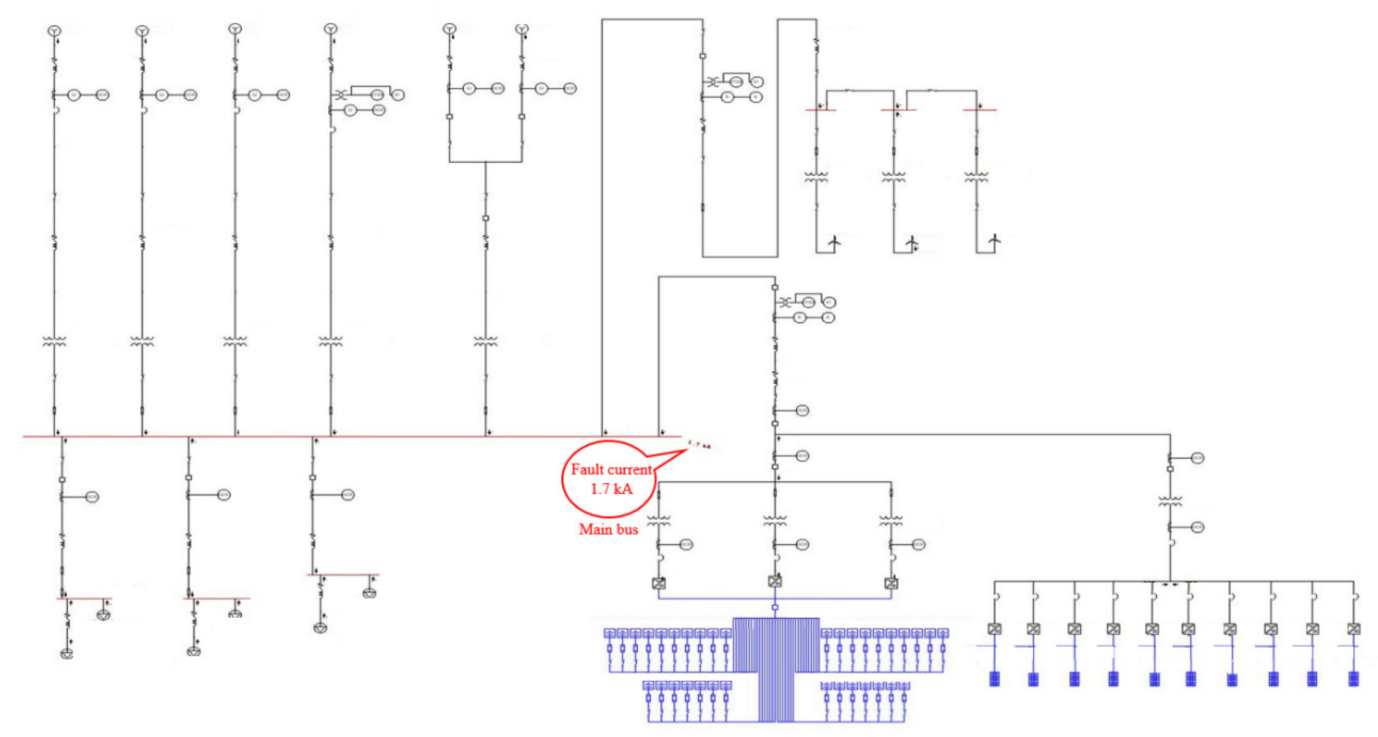

Figure 26. Simulation results of scenario 2: three-phase fault current calculation using ETAP.

\section{Discussion}

In the $13.8 \mathrm{kV}$ main bus for each scenario derived from the PSCAD/EMTDC and ETAP simulations, the error between both simulation results was about $0.23 \mathrm{kA}$ in the case of ground fault and about $0.1 \mathrm{kA}$ in the case of a three-phase fault. The negligible errors were caused by the different input parameters for each simulation's characteristics. From the simulation results under fault conditions, the validity of the simulation modeling was verified.

In scenario 2, since the switching of the PCS stopped, the required current capacities of the IGBTs were estimated from scenario 1 . Therefore, the capacities of each IGBT should be designed above the maximum current value shown in Table 2 to prevent the failure of a LVRT operation. In addition, the reason that the fault current was smaller in a three-phase fault than in the single ground fault, shown in Table 2, was because the voltage drop became more than $-70 \%$, as shown in Figure 3, so switching of the IGBT was dropped out.

Table 2. Maximum current flowing into the IGBTs.

\begin{tabular}{ccc}
\hline PCS & Single Ground Fault Current (kA) & Three-Phase Fault Current (kA) \\
\hline $\mathbf{1 0 0} \mathbf{~ k W ~ ( P V ) ~}$ & 0.6 & 0.5 \\
$\mathbf{5 0 0} \mathbf{~ k W}$ (ESS) & 0.7 & 0.6 \\
$\mathbf{8 0 0} \mathbf{~ k W}$ (Wind turbine) & 2.5 & 2.2 \\
\hline
\end{tabular}

As a result of using ETAP, the set values of the breaker and protective relay connected to each bus were derived. Firstly, the circuit breaker should be designed based on the value of the larger current among the single line ground fault and the three-phase short-circuit fault. Table 3 shows the values of the accident current flowing into the PV plant, ESS, and wind farm. From these results, the rated breaking capacities of circuit breakers should be selected as values above the maximum accident current.

Table 3. Selection of the rated current of the breaker.

\begin{tabular}{ccc}
\hline Items & Single Ground Fault Current (kA) & Three-Phase Fault Current (kA) \\
\hline PV plant side bus & 0.58 & 0.50 \\
ESS side bus & 1.28 & 1.07 \\
Wind farm side bus & 0.68 & 0.98 \\
\hline
\end{tabular}


Figure 27 shows the correction of the overcurrent relay number 15 connected to the ESS from the ETAP simulation results. It means that the relay operates with an inverse time limit, the time delay operation is set at $150 \%$ of the rated current, and the pick-up current is $1.18 \mathrm{kA}$. In addition, the delay time is $0.4 \mathrm{~s}$ based on the three-phase short-circuit fault current. If the fault current is up to $1.60 \mathrm{kA}$, it will operate within $50 \mathrm{~ms}$ with a definite time operation.

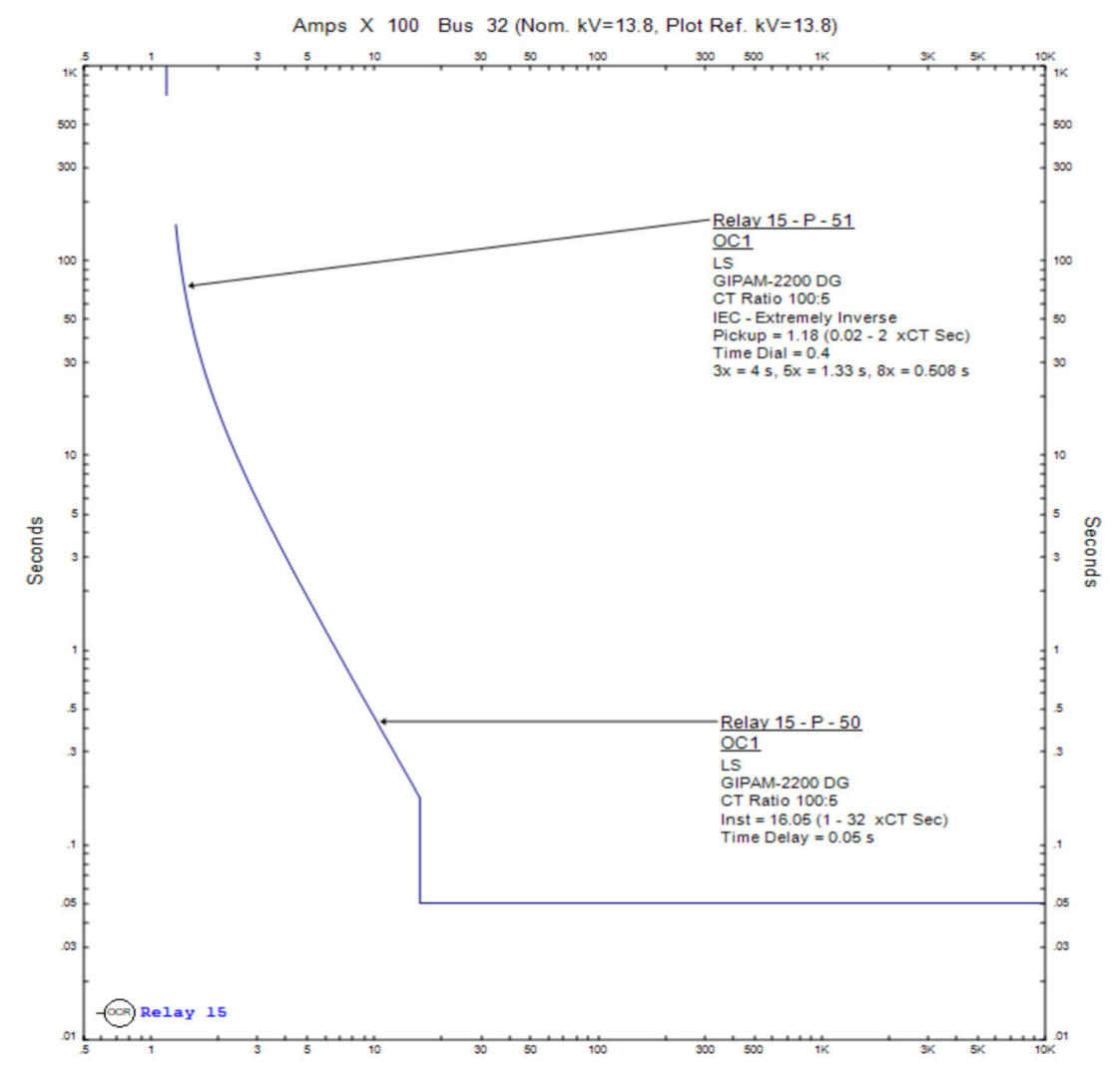

Figure 27. Protective relay correction time current curve.

\section{Conclusions}

In this study, we proposed a complete protection system of a microgrid using the PSCAD/EMTDC and ETAP programs to ensure a more stable microgrid operation. In the design example of the microgrid, the reliability of the simulation models was improved by cross-checking the accident current results between two simulation tools. PSCAD/EMTDC calculated the IGBT minimum withstand current value for each inverter for LVRT operation, which is essential for a microgrid. Through the ETAP analysis result, the fault current result value of the bus at the sensitive renewable facility side was derived from the overcurrent, and the minimum rated breaking capacity of each facility was suggested. Accordingly, the rated capacity of the circuit breaker should be designed to exceed the value of the fault current flowing into each bus. In addition, through ETAP, the characteristic curve of the protection relay connected to each bus can be derived. Through this, it was possible to derive the protective relay correction value according to the characteristics of each relay.

In this paper, through the PSCAD/EMTDC and ETAP system analysis programs, a method to simultaneously consider PCS LVRT operation, protection relay, and circuit breaker design methods was proposed. If the protection system of the microgrid is designed through various system analysis programs as shown above, stable operation of the power system will be possible in the future.

Author Contributions: Conceptualization: E.-H.K.; methodology: H.S. and S.H.C.; resources: H.S., S.H.C., and E.-H.K.; writing — original draft preparation: H.S. and S.H.C.; writing —review and editing: H.S. and E.-H.K.; supervision: E.-H.K. All authors have read and agreed to the published version of the manuscript. 
Funding: This research was funded by Jeju National University and the Korea Institute of Energy Technology Evaluation and Planning (KETEP).

Acknowledgments: This research was supported by the 2019 scientific promotion program funded by Jeju National University and the Korea Institute of Energy Technology Evaluation and Planning (Project number: 20194030202310).

Conflicts of Interest: The authors declare no conflict of interest.

\section{Nomenclature}

$\begin{array}{ll}V_{t d} & \text { d-axis terminal voltage } \\ V_{t q} & \text { q-axis terminal voltage } \\ V_{s d} & \text { d-axis grid voltage } \\ V_{s q} & \text { q-axis grid voltage } \\ i_{d} & \text { d-axis current } \\ i_{q} & \text { q-axis current } \\ S_{u x} & \text { Upper arm IGBT }(\mathbf{x}=\text { Phase } \mathbf{a}, \mathbf{b}, \mathbf{c}) \\ S_{l x} & \text { Lower arm IGBT }(\mathbf{x}=\text { Phase } \mathbf{a}, \mathbf{b}, \mathbf{c}) \\ i_{u x} & \text { Upper arm current }(\mathbf{x}=\text { Phase } \mathbf{a}, \mathbf{b}, \mathbf{c}) \\ i_{l x} & \text { Lower arm current }(\mathbf{x}=\text { Phase } \mathbf{a}, \mathbf{b}, \mathbf{c}) \\ L_{i} & \text { Filter inductance } \\ k_{p} & \text { Proportional gain } \\ k_{i} & \text { Integral gain } \\ \omega & \text { Grid's angular frequency } \\ \Delta \mathrm{V} & \text { Voltage error } \\ P_{r e f} & \text { Reference of active power } \\ Q_{r e f} & \text { Reference of reactive power } \\ I_{k} & \text { Initial symmetrical short-circuit current } \\ U_{n} & \text { Nominal voltage } \\ Z_{e q} & \text { Equivalent impedance } \\ i_{p} & \text { Peak short-circuit current } \\ \text { IEC } & \text { International Electrotechnical Commission } \\ \text { RMS } & \text { Root mean square } \\ \text { AC } & \text { Alternating current } \\ \text { DC } & \text { Direct current } \\ \text { ESS } & \text { Energy storage system } \\ \text { PCS } & \text { Power conversion system } \\ \text { LVRT } & \text { Low voltage ride through } \\ \text { IGBT } & \text { Insulated gate bipolar transistor } \\ \text { PV } & \text { Photovoltaic } \\ \text { WT } & \\ & \text { Wind turbine } \\ & \end{array}$

\section{References}

1. Hay, S.; Ferguson, A. A Review of Power System Modelling Platforms and Capabilities; IET Special Interest Publication for the Council for Science and Technology on, 2015. Available online: https://www.theiet.org/ media/1291/pnjv-3-15.pdf (accessed on 4 November 2020).

2. Mohammadhassani, A.; Teymouri, A.; Mehrizi-Sani, A.; Tehrani, K. Performance Evaluation of an Inverter-Based Microgrid under Cyberattacks. In Proceedings of the 2020 IEEE 15th International Conference of System of Systems Engineering (SoSE), Budapest, Hungary, 2-4 June 2020.

3. Kazerani, M.; Tehrani, K. Grid of Hybrid AC/DC Microgrids: A New Paradigm for Smart City of Tomorrow. In Proceedings of the 2020 IEEE 15th International Conference of System of Systems Engineering (SoSE), Budapest, Hungary, 2-4 June 2020.

4. Brucoli, M.; Green, T.C.; McDonald, J.D.F. Modelling and Analysis of Fault Behaviour of Inverter Microgrids to Aid Future Fault Detection. In Proceedings of the System of Systems Engineering, San Antonio, TX, USA, 16-18 September 2007. 
5. Niewind, J.; Hemdan, N.G.A.; Klosinski, C.; Kurrat, M.; Gerdinand, F.; Meisner, J.; Passon, S. PSCAD/EMTDC-based simulations for fault analysis and fault identification in 380V ring DC systems. In Proceedings of the 2017 IEEE Second International Conference on DC Microgrids, Nuremburg, Germany, 27-29 June 2017.

6. Zhang, Z.; Xiang, M.; Liu, Y.; Zhou, M. PSCAD/EMTDC based SVPWM inverter simulation. In Proceedings of the International Conference on Sustainable Power Generation and Supply, 2012., Hangzhou, China, 8-9 September 2012.

7. Farrokhabadi, M.; Canizares, C.; Bhattacharya, K. A voltage-based frequency controller for inverter-based systems in microgrids. In Proceedings of the 2016 IEEE Power and Energy Society General Meeting, Boston, MA, USA, 17-21 July 2016.

8. Farkhani, J.S.; Zareein, M.; Soroushmehr, H.; Mortazavi, H. Coordination of Directional Overcurrent Protection Relay for Distribution Network with Embedded DG. In Proceedings of the 2019 5th Conference on Knowledge Based Engineering and Innovation, Tehran, Iran, 28 February-1 March 2019.

9. Pathan, M.; Shah, A. Co-ordination of protective relays for 16MW load system using ETAP. In Proceedings of the 2017 International Conference on Energy, Communication, Data Analytics and Soft Computing, Chennai, India, 1-2 August 2017.

10. Freitas, W.; Morelato, A. Comparative Study between Power System Blockset and PSCAD / EMTDC for Transient Analysis of Custom Power Devices Based on Voltage Source Converter. In Proceedings of the 2003 International Conference on Power Systems Transients, New Orleans, USA, 28 September-2 October 2003.

11. Awalin, L.J.; Tasnim, T.; Tien, T.L.; Suyono, H. Comparison study of fault location on distribution network using PSCAD and DIgSILENT power factory by using matching approaches. Indones. J. Electr. Eng. Comput. Sci. 2020, 17, 78-85. [CrossRef]

12. Yang, S.; Franklin, G.A. Switching transient overvoltage study simulation comparison using PSCAD/EMTDC and EMTP-RV. In Proceedings of the IEEE Southeastcon, Orlando, FL, USA, 15-18 March 2012.

13. Li, Y.; Meng, K.; Dong, Z.Y.; Zhang, W. Sliding Framework for Inverter-Based Microgrid Control. IEEE Trans. Power Syst. 2020, 35, 1657-1660. [CrossRef]

14. Sahoo, A.K. Protection of microgrid through coordinated directional over-current relays. In Proceedings of the 2014 IEEE Global Humanitarian Technology Conference-South Asia Satellite, Trivandrum, India, 26-27 September 2014.

15. Sharma, A.; Panigrahi, B.K. Phase Fault Protection Scheme for Reliable Operation of Microgrids. IEEE Trans. Ind. Appl. 2017, 54, 2646-2655. [CrossRef]

16. Kadukar, P.R.; Shete, P.S.; Gawande, S.P. Transient Analysis of Distributed Generation AC Microgrid using ETAP. In Proceedings of the 2018 International Conference on Current Trends towards Converging Technologies, Coimbatore, India, 1-3 March 2018.

17. Dewadasa, M.; Ghosh, A.; Ledwich, G. Protection of microgrids using differential relays. In Proceedings of the 2011 the Australasian Universities Power Engineering Conference, Brisbane, QLD, Australia, 25-28 September 2011.

18. Lee, W.G.; Nguyen, T.T.; Yoo, H.J.; Kim, H.M. Low-Voltage Ride-Through Operation of Grid-Connected Microgrid Using Consensus-Based Distributed Control. Energies 2018, 11, 2867. [CrossRef]

19. Shin, H.; Jung, H.S.; Sul, S.K. Low Voltage Ride through(LVRT) control strategy of grid-connected variable speed Wind Turbine Generator System. In Proceedings of the 8th International Conference on Power Electronics-ECCE Asia, Jeju, Korea, 30 May-3 June 2011.

20. Peng, X.; Wang, W. A new lvrt method applied on the integration of distributed wind power generation. In Proceedings of the 2012 China International Conference on Electricity Distribution, Shanghai, China, 10-14 September 2012.

21. Micallef, A.; Staines, C.S. Voltage rise mitigation and low voltage ride through capabilities for grid-connected low voltage microgrids. In Proceedings of the 2017 19th European Conference on Power Electronics and Applications, Warsaw, Poland, 11-14 September 2017.

22. Georgious, R.; Garcia, J.; Sumner, M.; Saeed, S.; Garcia, P. Fault Ride-Through Power Electronic Topologies for Hybrid Energy Storage Systems. Energies 2020, 13, 257. [CrossRef]

23. Liu, W.; Gong, Y.; Geng, G.; Jiang, Q. Optimal control of PV ramp rate using multiple energy storage system. Refined ramp event characterisation for wind power ramp control using energy storage system. IET Renew. Power Gener. 2019, 13, 1731-1740. [CrossRef] 
24. Senarathna, T.S.S.; Hemapala, K.T.M.U. Optimized Adaptive Overcurrent Protection Using Hybridized Nature-Inspired Algorithm and Clustering in Microgrids. Energies 2020, 13, 3324. [CrossRef]

25. Baloch, S.; Jamali, S.Z.; Mehmood, K.K.; Bukhari, S.B.A.; Zaman, M.S.U.; Hussain, A.; Kim, C. Microgrid Protection Strategy Based on the Autocorrelation of Current Envelopes Using the Squaring and Low-Pass Filtering Method. Energies 2020, 13, 2350. [CrossRef]

26. Dogruer, T.; Tan, N. Design of PI Controller using Optimization Method in Fractional Order Control System. IFAC 2018, 51, 841-846. [CrossRef]

27. Yaniv, O.; Nagurka, M. Robust pi controller design satisfying sensitivity and uncertainty specifications. IEEE Trans. Autom. Control 2003, 48, 2069-2072. [CrossRef]

28. Operation Technology, Inc. ETAP 16 User Guide 2016; Operation Technology, Inc.: Irvine, CA, USA, 2016.

29. Ntare, R.; Abbasy, N.H.; Youssef, K.H.M. Low Voltage Ride through Control Capability of a Large Grid Connected PV System Combining DC Chopper and Current Limiting Techniques. J. Power Energy Eng. 2019, 7, 62-79. [CrossRef]

30. Jin, Y.; Wu, D.; Ju, P.; Rehtanz, C.; Wu, F.; Pan, X. Modeling of Wind Speeds Inside a Wind Farm with Application to Wind Farm Aggregate Modeling Considering LVRT Characteristic. IEEE Trans. Energy Convers. 2020, 35, 508-519. [CrossRef]

Publisher's Note: MDPI stays neutral with regard to jurisdictional claims in published maps and institutional affiliations.

(C) 2020 by the authors. Licensee MDPI, Basel, Switzerland. This article is an open access article distributed under the terms and conditions of the Creative Commons Attribution (CC BY) license (http://creativecommons.org/licenses/by/4.0/). 